\title{
A DYNAMIC MODEL OF SUBPRIME MORTGAGE DEFAULT: ESTIMATION AND POLICY IMPLICATIONS
}

\author{
Patrick Bajari \\ Chenghuan Sean Chu \\ Denis Nekipelov \\ Minjung Park \\ Working Paper 18850 \\ http://www.nber.org/papers/w18850 \\ NATIONAL BUREAU OF ECONOMIC RESEARCH \\ 1050 Massachusetts Avenue \\ Cambridge, MA 02138 \\ February 2013
}

We would like to thank seminar participants at Stanford GSB, Chicago Booth, Olin Business School, Berkeley ARE and IO fest for valuable comments. The views expressed are those of the authors and do not necessarily reflect the official positions of the Federal Reserve System or the National Bureau of Economic Research.

NBER working papers are circulated for discussion and comment purposes. They have not been peerreviewed or been subject to the review by the NBER Board of Directors that accompanies official NBER publications.

(C) 2013 by Patrick Bajari, Chenghuan Sean Chu, Denis Nekipelov, and Minjung Park. All rights reserved. Short sections of text, not to exceed two paragraphs, may be quoted without explicit permission provided that full credit, including $(\odot)$ notice, is given to the source. 
A Dynamic Model of Subprime Mortgage Default: Estimation and Policy Implications Patrick Bajari, Chenghuan Sean Chu, Denis Nekipelov, and Minjung Park

NBER Working Paper No. 18850

February 2013

JEL No. C14,C5,G21

\begin{abstract}
$\underline{\text { ABSTRACT }}$
The increase in defaults in the subprime mortgage market is widely held to be one of the causes behind the recent financial turmoil. Key issues of policy concern include quantifying the role of various factors, such as home price declines and loosened underwriting standards, in the recent increase in subprime defaults and predicting the effects of various policy instruments designed to mitigate default. To address these questions, we estimate a dynamic structural model of subprime borrowers' default behavior. We prove that borrowers'time preference is identified in our model and propose an easily implementable semiparametric plug-in estimator. Our results show that principal writedowns have a significant effect on borrowers' default behavior and welfare: a uniform 10\% reduction in outstanding mortgage balance for the pool of borrowers in our sample would reduce the overall default probability by $22 \%$, and borrowers'average willingness to pay for the principal writedown would be $\$ 16,643$

Patrick Bajari

University of Washington

331 Savery Hall

UW Economics Box 353330

Seattle, Washington 98195-3330

and NBER

Bajari@uw.edu

Chenghuan Sean Chu

Federal Reserve Board of Governors

20th Street and Constitution Avenue NW

Washington, DC 20551

sean.chu@frb.gov

Denis Nekipelov

UC, Berkeley

530 Evans Hall, \#3880

Berkeley, CA 94720-3880

nekipelov@econ.berkeley.edu

Minjung Park

Haas School of Business

UC Berkeley

545 Student Services Building \#1900

Berkeley

CA 94720-1900

minjungp@gmail.com
\end{abstract}




\section{Introduction}

The collapse of the subprime mortgage market and its subsequent role in triggering the current recession lend special importance to understanding the key drivers behind the increase in defaults. Much of the debate during the crisis aftermath has centered on the efficacy of various government interventions designed to reduce default, and whether an expansion in the scope of such programs would be desirable. The answers to these questions critically depend upon how borrowers' default behavior would respond to various incentives.

For example, the Home Affordable Refinance Program (HARP), introduced in 2009, streamlines refinancing for underwater borrowers with "conforming" loans backed by the government-sponsored enterprises (GSEs) Fannie Mae and Freddie Mac. An expansion of the program to nonconforming loans could reduce the incentive to default by negative-net equity borrowers, but could also potentially become a liability to the GSEs (and to taxpayers) if the frequency of default after refinancing turns out to be more common for the expanded eligible pool than anticipated. Similarly, the Home Affordable Modification Program (HAMP), also introduced in 2009, aims to reduce mortgage payments by delinquent borrowers to no more than 31 percent of monthly income, through a combination of interest rate reductions, principal writedowns, and loan maturity extensions. Neither HAMP nor its predecessor, Hope for Homeowners, which was introduced a year earlier and focused exclusively on principal writedowns, has been a great success, in part due to widespread redefault following mortgage modification. ${ }^{2}$ Just as important, policymakers have struggled to understand the limited degree of lenders' participation in these programs. Very few lenders have been willing to modify mortgages under HAMP or Hope for Homeowners. Participation in HARP has been somewhat greater, but still far less than anticipated. In this paper, we aim to understand the determinants of borrowers' default behavior. This will allow policymakers to predict how borrowers' default decisions would respond to various features of such programs. The predictions could then be used as a key input to understanding how those features might affect lenders' participation incentives.

In answering these questions, it is critical to recognize that default decisions are inherently dynamic due to the irreversibility of default and the option value associated with being able to default at some point in the future. In this context, descriptive analysis does not provide enough information to either quantify the importance of various factors behind the recent surge in defaults or determine the impact of implementing policy interventions. Furthermore, failure to take into account how borrowers' dynamic incentives are affected by policy interventions could lead to misleading welfare analysis and the adoption

\footnotetext{
${ }^{2}$ See, for example, United States Department of Treasury report on "The Effects of Principal Reduction on HAMP Early Redefault Rates" (2012), available at http://www.treasury.gov/resource-center/economicpolicy/Documents/HAMPPrincipalReductionResearchLong070912FINAL.pdf.
} 
of ineffective policies. Therefore, we design a dynamic structural model of subprime borrowers' default behavior, estimate it using a unique dataset and use this model for market evaluation and comparative analysis of a number of proposed policies for mitigating subprime mortgage default.

Our model has four key elements. First, the model is dynamic: borrowers are forward-looking and respond to current shocks as well as expected future shocks by adjusting their default behavior. Second, the choice set of the borrowers is discrete, whereby in each period the borrower chooses whether to default on a loan, to prepay (or refinance) the loan, or to continue making just the regularly scheduled payments. We consider default to be a terminal action, resulting in the borrower receiving a one-time "compensation" (or rather, utility loss) and no future utility flows, and the dynamic problem coming to an end. The assumption that default is terminal has important implications for identification and estimation of the model. Third, the borrower's decision problem has a finite horizon, reflecting the fact that mortgages have a fixed maturity, commonly 30 years. This makes our model different from the infinite-horizon setup that is more commonly seen in the literature. Fourth, our model is a single-agent model that abstracts from potential interactions among borrowers. We endow our model with these features in order to provide a realistic and tractable framework for borrowers' default decisions. The resulting model bears some resemblance to that of the dynamic discrete choice literature such as Rust (1987), Magnac and Thesmar (2002), and Gowrisankaran and Rysman (2012).

Our empirical analysis employs a rich dataset from LoanPerformance, which is uniquely geared toward addressing our questions due to the level of detail it contains. The data cover the majority of subprime and Alt-A mortgages ${ }^{3}$ securitized between 2000 and 2007. The unit of observation is an individual mortgage observed at a point in time. For each loan, we observe information from the borrower's loan application, including the terms of the contract, the appraised value of the property, the loan-to-value (LTV) ratio, the level of documentation, and the borrower's credit score at the time of origination. We also observe the month-by-month stream of payments made by the borrower and whether the mortgage goes into default or is prepaid. To track movements in home prices, we merge the mortgage data with zip code level home price indices.

Our empirical approach makes several methodological advances. First, we develop an estimation procedure for finite horizon optimal decision problem with more than two periods which has not been done before and is conceptually very different from estimation of infinite horizon problems. Such problems must take into account the nonstationarity of the optimal decision rules due to the presence of a final period. Our estimation method has a multi-step structure, as in Hotz and Miller (1993). Our estimation

\footnotetext{
${ }^{3}$ Alt-A's are mortgages that are considered riskier than prime but less risky than subprime. In this paper, we casually use the term "subprime market" to refer to both subprime and Alt-A mortgages. The distinction between the two is in any case somewhat artificial.
} 
method is intuitive and based on iterated application of a linear (or nonlinear) projection. There are two main advantages to our approach. From the technical perspective, our method does not require forward simulation and only requires us to make one-period-ahead predictions of borrowers' decisions, making it easy to implement using standard statistical software such as STATA. From the conceptual economic perspective, we do not require the borrowers to form precise long-term forecasts for the transition of state variables: our setup only requires that borrowers can form one-period-ahead expectations regarding the state variables and that their preferences be stable. Furthermore, we nonparametrically estimate oneperiod-ahead expectations and use the estimates to recover economic agents' preferences. This approach is closely related to work in Ahn and Manski (1993), and thus conceptually our approach can be considered as extending Manski (1991), Manski (1993) and Manski (2000), which examine responses of economic agents to their expectations in models with uncertainty or endogenous social effects, to the case where the problem of the economic agent is dynamic. Our approach also conveniently accommodates the limitations of our data: it circumvents the problems posed by the lack of observations close to the final period, which characterizes our data because subprime mortgages were only introduced in recent years.

Our second methodological contribution consists of some new results on the (semiparametric) identification of finite-horizon dynamic discrete decision problems. One of the most interesting results pertains to identification of borrowers' time preferences. Identification of the discount factor comes from the fact that time to loan maturity influences ex ante value functions but does not have any impact on period utility. Instead of assuming an arbitrary number for the discount factor, as is typically done in the literature, we present an estimate of time preferences of subprime mortgage borrowers.

Our structural estimates provide a clue to understanding the relative importance of different drivers of default as well as the potential effects of several broad classes of policy interventions for mitigating default. To obtain the answer we use the estimated optimal decision rules of borrowers to analyze their behavior under various "counterfactual" regimes. Our approach differs from the standard approach, which is to compute the counterfactual outcomes by re-solving for the optimal behavior using estimates of the structural parameters. ${ }^{4}$ The usual argument for re-solving for the optimal behavior is to address the Lucas critique. However, the individual-level panel structure of our data allows us to avoid the Lucas critique as long as we judiciously choose our counterfactual scenarios. Because the panel structure allows us to identify the individual optimal decision rules over a very wide range of state variables, so long as a policy intervention results in state-variable realizations that are actually observed for a subset of borrowers in the data (i.e., the realizations remain within sample) and does not change the state

\footnotetext{
${ }^{4}$ We decided to take this approach mainly due to the data constraint posed by lack of observations for loans close to maturity. In order to re-solve for the optimal behavior, we must use backward induction starting from the last period of loan maturity. Because our estimates of the utility function are based on data from more recently originated loans, we would need to assume that the estimated period utility function from younger loans also applies to loans in their final period, an assumption we believe to be too strong as discussed in Section 3.
} 
transition process (or borrowers' expectation about it), the new optimal behavior is correctly captured by the estimated decision rules of borrowers.

As we might expect, the downside of this approach is that it cannot be used to analyze scenarios involving transitions to states not spanned by the estimation sample or resulting in changes to the state transitions themselves. Nevertheless, we illustrate that there are many interesting scenarios that can be fruitfully explored without re-solving for the new optimal behavior. For example, we are able to study the effects of interventions that boost housing prices, so long as the resulting housing price evolution is observed in some geographic area within the actual sample. This is not a restrictive assumption, given the wide diversity of housing price evolution paths in different metropolitan areas. Also, policymakers have proposed a variety of interventions at the level of individual mortgages, including subsidies for lenders to forgive mortgage principal and caps on permissible loan-to-value ratios. We can study the effects of most of these interventions so long as the features of a counterfactual mortgage are within the empirical support of our data. ${ }^{5}$ This approach is computationally much lighter than having to re-solve for the new optimal behavior using backward induction.

We examine the effect of each counterfactual scenario on default behavior. Using the structural estimates, we also determine welfare consequences for the borrowers. In particular, we compute the one-time income compensation that is necessary to bring borrowers' ex ante value function under the counterfactual scenario back to its original level, which is a measure of compensating variation in our dynamic setting. For instance, our results show that a uniform $10 \%$ reduction in outstanding mortgage balance for the pool of borrowers in our sample would reduce the overall default probability by $22 \%$, and that borrowers' average willingness to pay for the principal writedown would be $\$ 16,643$.

This paper contributes to the literature analyzing the mortgage market by estimating a fully dynamic, structural model of borrower behavior. Most of existing empirical work on mortgage defaults uses a duration framework (Deng, Quigley and van Order (2000); Foster and Van Order (1984); Tracy and Wright (2012)), which does not take into account the impact of current actions on future payoffs or the impact of expectations about the future on current actions. The prior literature has established the importance of considering consumers' forward-looking behavior in credit and insurance markets more generally (Einav, Jenkins and Levin (2012); Aron-Dine et al. (2012); Einav et al. (2013)). Estimating a dynamic structural model informs our understanding of borrowers' default incentives, and allows us to evaluate welfare effects of key policy tools, a topic of immense interest to policymakers. The paper also adds to the growing list of research on the subprime mortgage crisis, such as Foote et al. (2008), Demyanyk and van Hemert (2011), Keys et al. (2010), Gerardi et al. (2008), and Bajari, Chu and Park

\footnotetext{
${ }^{5}$ As a counterexample, we cannot study loan modifications that extend the duration of the loan to lengths not observed in the sample, such as from 30 years to 45 years.
} 
(2011) among others.

In addition, the paper makes a contribution to the literature on identification of time preferences (Magnac and Thesmar (2002); Fang and Wang (2012)) by proving identification of the discount factor in our finite horizon model even when researchers do not have data on the final period. Unlike our paper, most of the prior literature that estimates time preferences relies on experimental data (see Frederick, Loewenstein and O'Donohue (2002) for a review of the literature). ${ }^{6}$

The rest of this paper proceeds as follows. In Section 2, we describe the data. In Section 3, we present our model and discuss identification of the model primitives, including the discount factor. Section 4 discusses our estimation methodology and its sampling properties. Section 5 presents estimation results. In Section 6, we discuss our counterfactual exercises and welfare implications for borrowers. Section 7 concludes.

\section{Data}

We use data from LoanPerformance on subprime and Alt-A mortgages that were originated between January 2000 and September 2007 and securitized in the private-label (i.e., non-GSE) market. The data cover more than $85 \%$ of all securitized subprime and Alt-A mortgages.

For each loan, we observe the loan terms and borrower characteristics reported at the time of origination, such as the type of mortgage (fixed rate, adjustable rate, etc.), the initial contract interest rate, the level of documentation (full, low, or none ${ }^{7}$ ), the appraised value of the property, the LTV ratio, the location of the property by zip code, and the borrower's FICO score.

We focus on 30-year fixed-rate mortgages, the most common mortgage type. We further restrict our sample to loans that are first liens and that are for properties located in 20 major Metropolitan Statistical Areas (MSAs). ${ }^{8}$ We also exclude "cash-out" refinance loans ${ }^{9}$ from our sample and focus on loans that are for home purchases or refinances with no cash out. Many homeowners use cash-out refinance loans for debt consolidation or home improvement, which would significantly change their non-housing-debts

\footnotetext{
${ }^{6}$ A few exceptions are Hausman (1979), Yao et al. (2012), and Chung, Steenburgh, and Sudhir (2011).

${ }^{7}$ Full documentation indicates that the borrower's income and assets have been verified. For low documentation loans, only certain information about assets has been verified. No documentation indicates there has been no verification of information about either income or assets.

${ }^{8}$ Atlanta, Boston, Charlotte, Chicago, Cleveland, Dallas, Denver, Detroit, Las Vegas, Los Angeles, Miami, Minneapolis, New York, Phoenix, Portland, San Diego, San Francisco, Seattle, Tampa, and Washington D.C.

${ }^{9}$ That is, when the borrower takes out a larger loan than needed to pay off the old loan. Our data identify individual loans and not the identities of borrowers, so we cannot identify the previous loan taken out by a particular borrower. However, the data identify whether the purpose of each loan was for a home purchase or a refinance, and whether cash was taken out on a refinance.
} 
or home value in a way we do not observe in the data. This makes our model less suitable for explaining the default behavior of borrowers with cash-out refinance loans.

We do not directly observe the borrower's income. Instead, we impute it based on the front-end debt-to-income ratio reported at the time of loan origination, and use it to proxy for the borrower's current income during each time period over the course of the loan. ${ }^{10}$ The front-end debt-to-income ratio is available for only a very small fraction (3.5\%) of all loans, significantly reducing our estimation sample. In earlier work (Bajari, Chu and Park (2011)) we found that this sample restriction did not affect key findings on borrowers' default behavior. Furthermore, even with this restriction, we still have about 12,000 borrowers in the sample. Hence, we use this sample in our empirical investigation. For more detailed discussions of the LoanPerformance data, see Demyanyk and van Hemert (2011) and Keys et al. (2010).

The data track each loan over the course of its life, reporting the outstanding balance, delinquency status, and scheduled payment in each month. We define default as occurring if the bank takes possession of the home or if the loan has been delinquent for 90 days or more, a commonly used definition of default in the mortgage literature. Default is a terminal event, so if a loan defaults in month $t$, it drops from the sample starting at $t+1$. We define prepayment as occurring if the loan balance is observed going to zero before maturity, presumably because the borrower has paid off the loan in full. We do not observe the new loan used to refinance the original loan, because our data identify individual loans but not the identities of specific borrowers. When the borrower prepays, we assume that the borrower refinances into a new loan. ${ }^{11}$ We assume that the new loan matures at the same maturity date as the old loan and has an interest rate equal to the current market interest rate. ${ }^{12,13}$ If the borrower does not default or prepay in month $t$, the borrower continues to make just the regularly scheduled payment, and the loan survives into the next month. We track the status of each loan in our sample through December 2009. Thus, we have data on default behavior for only up through the first ten years of each loan, although the loans have a maturity of 30 years, an issue we will return to later.

\footnotetext{
${ }^{10}$ We approximate the borrower's income by dividing the scheduled monthly payment by the front-end debt-to-income ratio, as reported at origination. The front-end ratio measures housing-related principal and interest payments, taxes, and insurance as a percentage of monthly income. The assumption that household income stays constant over time is a necessary approximation, given that we only have data on each borrower's circumstances at the time of origination.

${ }^{11}$ In practice, some borrowers may prepay because they have sold the house. From the data, we cannot distinguish between prepayments due to refinancing and prepayments due to home sales. It is our understanding that most subprime borrowers prepay in order to refinance into a new loan with lower interest rates.

${ }^{12}$ For example, if the borrower refinances when the loan is 50 months old, we assume that the new loan will mature in 310 months. In practice, borrowers typically refinance into a mortgage with a standardized maturity such as 30 years or 15 years. Since some people refinance into 15-year mortgages while others refinance into 30-year mortgages, our assumption is a reasonable approximation of the average outcome.

${ }^{13}$ We assume that the market interest rate available to borrower $i$ at time $t$ is equal to $r_{i, t}=r_{t}\left(z_{i, t}\right)+\xi_{i}$, where $r_{t}\left(z_{i, t}\right)$ is the prevailing rate available at time $t$ for loans with observable characteristics $z_{i, t}$, and $\xi_{i}$ is a borrower-specific spread that is constant over time. For a given borrower, we can identify $\xi_{i}$ as the residual from regressing the observed interest rate on the observed characteristics of the borrower's original loan.
} 
As a proxy for any potential disruptions in household income over the course of the loan, we use the unemployment rate at the county level. Data on monthly county-level unemployment rates come from the Bureau of Labor Statistics. If we observed individual employment status in every month, we would be able to identify defaults that occur due to income shocks. However, we are limited in our ability to do so due to the noisiness of our county-level proxy.

To track movements in home prices, we use housing price indices (HPI) at the zip code level, also from LoanPerformance. LoanPerformance reports the home price indices at a monthly frequency, and constructs them using the transaction prices of properties that undergo repeat sales at different points in time in a given zip code area. We impute the current value of a home by adjusting its appraised value at the time of origination by the index. Because home price declines are thought to be one of the main drivers behind the recent surge in mortgage defaults, and because there is a high degree of variation in home price movements across locations even within the same MSA, it is important to have home price data at a fine geographic level. Hence, we believe that the use of the zip code level HPI from LoanPerformance enhances the robustness of our results. By contrast, most previous studies on mortgages and housing markets in general have used the HPI from Case-Shiller, which is only at the MSA level. See Table 1 for variable definitions.

[Table 1 about here]

Table 2 reports summary statistics, both for the entire sample and separately according to the mode by which loans come to an end in the sample - by prepayment, by default, or by censoring at the end of the sample. Maturation is not a relevant category for our sample. As shown, default is associated with lower income borrowers and lower credit scores. For instance, the average FICO score among all loans is 672.6 , compared with an average of 626.4 conditional on default.

[Table 2 about here]

The second panel of Table 2 presents summary statistics for time-varying variables as of the last period in which we observe each loan. Relative to the overall average across all borrowers, borrowers who default tend to have less net equity and lower housing value at the point of default. For instance, the amount of net equity in the last observed period is on average $\$ 103,000$ among all borrowers, but only $\$ 38,000$ for loans that default.

Table 2 also reports the share of loans for home purchases as opposed to no-cash-out refinances, as well as the share of loans to borrowers who intend to live in the house (owner-occupiers) versus people who 
buy the house for investment purposes (investors). These partitions of borrowers will become important later when we discuss borrower heterogeneity.

Table 3 shows that loan characteristics differ significantly across origination years. If loans of different vintages do not systematically differ from each other and home price transitions are uniform over time, we would expect that the fraction of loans that default by December 2009 (the end of the sample period) should be monotonically decreasing as we move to the right in Table 3, because loans from earlier vintages have had more time over which to default. Instead, we see that the fraction of loans that default by December 2009 is much higher for loans from the 2005-2007 vintages compared with loans originated in 2000-2004, suggesting that the later loans were riskier. This difference can be partly explained by differences in observable loan characteristics and by the decline in home prices in later years. However, loan characteristics and home price transitions might not fully explain the differences across origination years, as researchers have found that loans originated in the later years have a higher propensity to default even after controlling for these factors (Demyanyk and van Hemert (2011)). To account for any systematic differences in unobservable characteristics, we include origination year dummies in the state vector.

[Table 3 about here]

Table 4 reports the empirical distribution of the time to default, conditional on a loan eventually defaulting (upper panel), and the empirical distribution of the time to prepayment for loans that eventually prepay (lower panel). Both distributions have a hump shape. A similar hump shape in the default hazard and prepayment hazard is also well-documented in the mortgage literature ${ }^{14}$ (Gerardi et al. (2008); von Furstenberg (1969)), but there is no agreement in the literature on what economic forces lead to the initial increase in default hazard. It could be generated by borrowers' stronger determination to make payments on loans that they have just obtained (due to some behavioral biases, for instance) or by greater uncertainty about income or employment shocks further into the future (e.g., conditional on a lender approving a loan, presumably the borrower has a steady income in most cases. An unexpected income shock is thus likelier 18 months down the road as opposed to just after origination). In one of the alternative specifications we examine below, we modify our analysis to address the impact of such time-varying unobserved factors on our results.

[Table 4 about here]

${ }^{14}$ This effect is also confirmed by unreported regressions using our data. All unreported results are available upon request. 
While many of the state variables listed in Table 1 are time-invariant, three of them-home value, market interest rate and unemployment rate - stochastically evolve over time. ${ }^{15}$ These state variables are nonstationary (based on an independent analysis of their time series behavior), but we can estimate their transition paths in terms of the growth rate in home value and the first differences in market interest rate and unemployment rate, which are stationary.

Our analysis assumes that the regulatory regime remained constant over the sample period. In particular, we assume that borrowers do not experience or expect changes to their mortgages due to various foreclosure mitigation programs that the United States government implemented in the later stages of the housing crisis. Two major programs would conceivably be relevant to loans resembling those in our sample. Hope for Homeowners (based on legislation in Spring 2008) is a principal writedown policy. Due to lenders' apparent unwillingness to reduce principal, there has been virtually no participation in the program. The Home Affordable Modification Program (HAMP, based on legislation in 2009) is a payment-reduction program. However, most institutions started their HAMP trials in late 2009, largely after our sample period. ${ }^{16}$ Furthermore, since these programs have had extremely low take-up rates, it is a reasonable approximation to assume that borrowers did not expect to benefit from participation in such programs.

\section{Model of Borrowers' Behavior}

We formalize borrowers' decision process using a dynamic, discrete-time, single-agent model. Each agent enters a mortgage contract lasting $T$ time periods, and solves a dynamic programming problem with a finite time horizon ending at $T$. The components of the model are as follows.

\subsection{Actions}

At each time period $t$ over the life of borrower $i$ 's loan, the borrower chooses an action $a_{i, t}$ from the finite set $A=\{0,1,2\} .{ }^{17}$ The possible actions in $A$ are to default $\left(a_{i, t}=0\right)$, to prepay the mortgage $\left(a_{i, t}=1\right)$, or to make just the regularly scheduled payment for the current time period, which we refer to

\footnotetext{
${ }^{15}$ Net equity also stochastically evolves over time. Its evolution is determined by the evolution of home value and the evolution of the outstanding loan principal. Because the outstanding principal follows a deterministic evolution fully specified by the contractual interest rate (fixed over time) and loan maturity (also fixed over time), estimating the evolution of home value is sufficient to infer the evolution of net equity.

${ }^{16}$ A third program, the Home Affordable Refinance Program (HARP, based on legislation in 2009), makes it easier for borrowers to refinance, but is irrelevant to the subprime loans in our sample because it only applies to loans guaranteed by GSEs.

${ }^{17}$ Note that we use $t$ to denote the loan's age, not calendar time. A 36-month old loan will have $t=36$ whether the loan was originated in January 2003 or October 2007. In our estimation, we limit our attention to all loans with the same maturity (30 years), so loans with the same $t$ have the same number of months remaining until maturity.
} 
as "paying" $\left(a_{i, t}=2\right)$. We assume that there is no interaction among borrowers affecting their payoffs, so our setup is a single-agent model, not a game. We assume that default is a terminal action: once a borrower defaults, there is no further decision to be made and no further flow of utility starting from the next period.

\subsection{Period Utility and State Transition}

Each borrower observes a vector of state variables $s_{i, t} \in \mathcal{S}$ in each period. The support $\mathcal{S}$ is a product space that is a subset of $k$-dimensional Euclidean space. We allow the subspaces of this product space to be either continuous or discrete. The state vector $s_{i, t}$ includes borrower $i$ 's characteristics, the current home value, monthly payments, etc. We also allow this vector to contain lags of the current period's observable state variables. $s_{i, t}$ is fully observed by the econometrician. We assume that the borrower is also characterized by a time-invariant "type" $c_{i} \in \mathcal{C}$ (observed by the econometrician) and a timedependent vector of idiosyncratic shocks associated with each action $\varepsilon_{i, t}=\left(\varepsilon_{i, 0, t}, \varepsilon_{i, 1, t}, \varepsilon_{i, 2, t}\right)$ (unobserved by the econometrician). The set $\mathcal{C}$ is assumed to be finite. Although certain elements of $s_{i, t}$ may also be time-invariant, the purpose of defining a separate type space $\mathcal{C}$ will become apparent in Section 4 where we discuss our utility specification with random coefficients. Each element of $\varepsilon_{i, t}$ is assumed to have a continuous support on the real line. We make the following assumption regarding the marginal distributions of the random variables.

\section{ASSUMPTION 1}

(i) Conditional independence of the idiosyncratic payoff shocks: $s_{i, t} \perp \varepsilon_{i, t} \mid c_{i}$.

(ii) Conditional independence over time of idiosyncratic payoff shocks: $\varepsilon_{i, t}\left|\varepsilon_{i, t-1}, a_{i, t-1}, c_{i} \sim \varepsilon_{i, t}\right| a_{i, t-1}, c_{i}$.

(iii) Exclusion restriction ( $c_{i}$ cannot be represented as a linear combination of the elements of $\left.s_{i, t}\right): \mathcal{C}$ does not belong to any proper linear subspace of $\mathcal{S}$.

(iv) Markov transition of the state variables: $s_{i, t}$ follows a reversible Markov process, conditional on $a_{i, t}$.

In our empirical analysis we use a conventional specification of the distribution of the idiosyncratic shocks, assuming that components of $\varepsilon_{i, t}$ are mutually independent, have a type I extreme value distribution, and are i.i.d. across borrowers and over time. However, this assumption is not essential, and we establish the existence of an optimal strategy and prove our identification results for an arbitrary continuous distribution of random shocks that satisfy Assumption 1. 
Among the state variables, the monthly payment due and the contractual interest rate are the only ones whose transition is influenced by $a_{i, t}$. As mentioned in Section 2, we assume that when a borrower $i$ prepays in period $t$, he refinances into a new loan that matures at the same time as the old loan and whose contractual interest rate is equal to the current market interest rate. Thus, the payment level and contractual interest rate will depend upon the borrower's choice. We allow the state variables to follow a high-order Markov process by including the lagged state variables from the previous periods into the vector $s_{i, t}$. This structure allows us to provide a more realistic empirical model for important state variables such as the housing prices, which exhibit lag dependence.

We assume that the per-period utility of the borrower is separable in the idiosyncratic shock component. We can characterize the borrower's utility as:

$$
\begin{aligned}
& U\left(a_{i, t}, s_{i, t} ; c_{i}\right)=u\left(a_{i, t}, s_{i, t} ; c_{i}\right)+\varepsilon_{i, a_{i, t}, t}, \quad \text { for } t<T, \\
& U\left(a_{i, t}, s_{i, t} ; c_{i}\right)=u_{T}\left(a_{i, t}, s_{i, t} ; c_{i}\right)+\varepsilon_{i, a_{i, t}, t}, \quad \text { for } t=T \text {. }
\end{aligned}
$$

As specified, the per-period utility has a deterministic component, $u(\cdot, \cdot ; \cdot)$, which is a time-invariant function of the action, state, and the borrower's type. The payoff function in the final period can in general differ from that of earlier periods, capturing the fact that the borrower obtains full ownership of the house once the mortgage is fully paid off at maturity, which we can think of as adding a lump-sum boost to the period utility in the final period. Therefore, $u(\cdot, \cdot ; \cdot)$ may generally differ from $u_{T}(\cdot, \cdot ; \cdot)$.

As we demonstrate later in this section, normalization of the per-period payoff of one of the actions, typically required in discrete choice models, is not innocuous in dynamic discrete choice models like ours. Thus, we need to normalize the utility from one of the actions in a way that reflects economic conditions faced by the agents. ${ }^{18}$

\subsection{Decision Rule and Value Function}

We consider the borrower's problem as an optimal stopping problem, and assume that the default decision is irreversible and that the borrower cannot "re-start" borrowing after default. This assumption is realistic because default usually so damages a borrower's credit that borrowing for another house is impossible for a long time. And even if this were not the case, we could still interpret the borrower's dynamic decision problem as being over the timing of payment and default on a mortgage taken out on a particular house:

\footnotetext{
${ }^{18}$ It turns out that the observed decisions fully characterize the utilities from all choices and thus no normalization is necessary if (a) $u_{T}(\cdot, \cdot ; \cdot)=u(\cdot, \cdot ; \cdot)$ (i.e., the final period's utility function is the same as the utility function of earlier periods) and (b) the actions in the final period are observed for some of the borrowers in addition to the actions from earlier periods. Although these conditions do not apply to our empirical setup, there may be finite-horizon dynamic problems in other economic settings in which these two conditions are naturally satisfied. Thus, we consider such scenarios as a separate case in our identification discussions below.
} 
default would entail loss of the house, and the assumption of irreversibility would imply that the borrower cannot reacquire the same house following default. Provided that the default ("stopping") decision is irreversible, the choice of the default option is equivalent to taking a one-time "compensation" (more specifically, a utility loss) without future utility flows. If the borrower pays or refinances his mortgage, he receives the corresponding period payoff (which is a combination of utility from consumption of housing services and disutility from payments for the mortgage) plus the expected discounted stream of future utility. Parameter $\beta$ is the discount factor that characterizes the time impatience of the borrower.

The borrower's decision rule $D_{t}$ for each period $t$ is a mapping from the vector of payoff-relevant variables into actions, $D_{t}: \mathcal{S} \times \mathcal{C} \times \mathbb{R}^{3} \mapsto A$. We denote the borrower's decision probabilities by $\sigma_{t}\left(k \mid s_{i, t}, c_{i}\right)=$ $E\left[\mathbf{1}\left\{D_{t}\left(s_{i, t}, c_{i}, \varepsilon_{i, t}\right)=k\right\} \mid s_{i, t}, c_{i}\right]$ for $k \in A$. We collect $\sigma_{t}\left(k \mid s_{i, t}, c_{i}\right)$ for all $k$ and $t$ such that $\sigma_{t}\left(s_{i, t}, c_{i}\right)=$ $\left[\sigma_{t}\left(k=0 \mid s_{i, t}, c_{i}\right), \sigma_{t}\left(k=1 \mid s_{i, t}, c_{i}\right), \sigma_{t}\left(k=2 \mid s_{i, t}, c_{i}\right)\right]$ and $\sigma=\left(\sigma_{1}\left(s_{i, 1}, c_{i}\right), \ldots, \sigma_{T}\left(s_{i, T}, c_{i}\right)\right)$, and refer to $\sigma$ as the policy function.

Considering the expected discounted sum of utility of the borrower who has not defaulted prior to period $t<T$, we introduce the ex ante value function:

$$
V_{t, \sigma}\left(s_{i, t} ; c_{i}\right)=E_{\sigma, f(s)}\left[\sum_{\tau=t}^{T}\left(\beta^{\tau-t} U\left(a_{i, \tau}, s_{i, \tau} ; c_{i}\right) \prod_{\tau_{1}=1}^{\tau-1} 1\left(a_{i, \tau_{1}}>0\right)\right) \mid s_{i, t}, c_{i}\right]
$$

where $f(s)$ represents the state transitions. The term $\prod_{\tau_{1}=1}^{\tau-1} 1\left(a_{i, \tau_{1}}>0\right)$ reflects that once a borrower defaults, there is no further flow of utility starting from the next period.

The choice-specific value function, denoted by $V_{t, \sigma}\left(a_{i, t}=k, s_{i, t} ; c_{i}\right)$, corresponds to the deterministic component of the discounted sum of payoffs that the borrower receives when choosing action $k$ in period $t$ :

$$
\begin{aligned}
& V_{t, \sigma}\left(a_{i, t}=k, s_{i, t} ; c_{i}\right)=u\left(a_{i, t}=k, s_{i, t} ; c_{i}\right)+\beta E\left[V_{t+1, \sigma}\left(s_{i, t+1} ; c_{i}\right) \mid s_{i, t}, c_{i}, a_{i, t}=k\right] \text { for } t<T \\
& V_{t, \sigma}\left(a_{i, t}=k, s_{i, t} ; c_{i}\right)=u_{T}\left(a_{i, t}=k, s_{i, t} ; c_{i}\right) \text { for } t=T
\end{aligned}
$$

In particular, the choice-specific value of default is equal to the period utility of default, i.e., $V_{t, \sigma}\left(a_{i, t}=\right.$ $\left.0, s_{i, t} ; c_{i}\right)=u\left(a_{i, t}=0, s_{i, t} ; c_{i}\right)$ for $t<T$, because default is a terminal action, which makes the future value term $E\left[V_{t+1, \sigma}\left(s_{i, t+1} ; c_{i}\right) \mid s_{i, t}, c_{i}, a_{i, t}=0\right]$ zero. 


\subsection{Optimal Policy Functions}

In the following theorem, we establish a formal existence and uniqueness result characterizing the borrower's optimal decision.

Theorem 1 Under Assumption 1 there exists a unique decision rule $D_{t}^{*}\left(s_{i, t}, c_{i}, \varepsilon_{i, t}\right)$ supported on $A$ for $t=1,2, \ldots, T$ that solves the maximization problem

$$
\sup _{\left(D_{1}, D_{2}, \ldots, D_{T}\right) \in A^{T}} V_{1, \sigma}\left(s_{i, 1} ; c_{i}\right) .
$$

Proof. Our argument uses backward induction. In the last period (at the mortgage maturity) the borrower faces a static optimization problem of choosing among $V_{T}\left(0, s_{i, T} ; c_{i}\right)+\varepsilon_{i, 0, T}, V_{T}\left(1, s_{i, T} ; c_{i}\right)+$ $\varepsilon_{i, 1, T}$, and $V_{T}\left(2, s_{i, T} ; c_{i}\right)+\varepsilon_{i, 2, T}$. The optimal decision delivers the highest payoff, yielding the decision rule $D_{T}^{*}\left(s_{i, T}, c_{i}, \varepsilon_{i, T}\right)=\arg \max _{k \in A}\left\{V_{T}\left(k, s_{i, T} ; c_{i}\right)+\varepsilon_{i, k, T}\right\}$. Provided that the payoff shocks are idiosyncratic and have a continuous distribution, the optimal choice probabilities are characterized by continuous functions of $\left(V_{T}\left(k, s_{i, T} ; c_{i}\right), k \in A\right)$. Knowing the optimal decision rule in period $T$, we can obtain the choice-specific value function in period $T-1$ as

$V_{T-1}\left(k, s_{i, T-1} ; c_{i}\right)=u\left(k, s_{i, T-1} ; c_{i}\right)+\beta E\left[\sum_{k^{\prime} \in A} \mathbf{1}\left\{D_{T}^{*}=k^{\prime}\right\}\left(V_{T}\left(k^{\prime}, s_{i, T} ; c_{i}\right)+\varepsilon_{i, k^{\prime}, T}\right) \mid s_{i, T-1}, c_{i}, a_{i, T-1}=k\right]$.

Provided that the $T^{t h}$ period optimal decision is already derived, the optimal decision problem in period $T-1$ becomes a static problem of choice among three alternatives. Its solution, again, trivially exists and is (almost surely) unique because the distribution of $\varepsilon_{i, T-1}$ is continuous. We iterate this procedure back to $t=1$.

If we specify that the distribution of idiosyncratic shocks has the standard type I extreme value distribution, then it is possible to express the probabilities of default, prepayment, and payment at a given state, type, and period $t \leq T$ in closed form, in terms of the choice-specific value functions and using the multinomial logit formulas. We can also obtain explicit expressions for the differences between choice-specific values for different actions in terms of (the logarithms of) the optimal choice probabilities via the Hotz-Miller inversion. ${ }^{19}$

In our model, we can identify the levels of the choice-specific values themselves, and not just the differences, because default is a terminal action, pegging the choice-specific value of default to a fixed function $u\left(a_{i, t}=0, s_{i, t} ; c_{i}\right)$. The easiest example to illustrate this is when the payoff from the default

\footnotetext{
${ }^{19}$ From here on we shall consider only the value functions and choice probabilities corresponding to the optimal decision rule, so we shall omit the subscript $\sigma$.
} 
option is trivially normalized to zero, that is, $u\left(a_{i, t}=0, s_{i, t} ; c_{i}\right)=0$. In this case we can recover the choice-specific value functions and the ex ante value function directly from the data. As we show below, our model is identified from the data as long as the payoff from default is set to a fixed function.

\section{5 (Semiparametric) Identification}

In this section we demonstrate that our model is identified from objects observed in the data, namely, the choice probability of each option, conditional on the current state and the borrower's observable type $\left(P_{t}\left(a_{i, t}=k \mid s_{i, t}, c_{i}\right)\right)$; and the transition distribution for the state variables, characterized by the conditional cdf $F\left(s_{i, t} \mid s_{i, t-1}, c_{i}, a_{i, t-1}\right)$.

The model's three structural elements are: (1) the deterministic component of the per-period payoff function, $u(\cdot, \cdot ; \cdot)^{20} ;(2)$ the time preference parameter $\beta$; and $(3)$ the conditional distribution of the idiosyncratic utility shocks to the borrowers, which have the type-specific joint $\operatorname{cdf} F_{\varepsilon}(\cdot \mid c)$. We shall argue that $u(\cdot, \cdot ; \cdot)$ is nonparametrically identified and that the time preference parameter $\beta$ is identified, for a given distribution of the idiosyncratic payoff shocks satisfying Assumption 1. We emphasize that our identification results do not rely on the extreme value assumption regarding the distribution of the idiosyncratic shocks.

We show the model is identified by demonstrating that there exists a unique mapping from the observable distribution of the data to the structural parameters. We start with the case in which the payoff from the default option is known, and then consider relaxing this assumption.

Theorem 2 (Identification with fixed, known default utility) Suppose that the payoff from the default option is a fixed, known function $u(0, \cdot ; c)$, and that the distribution of idiosyncratic shocks conditional on the borrower-specific heterogeneity variables $c, F_{\varepsilon}(\cdot \mid c)$, has a full support with the density strictly positive on $\mathbb{R}^{3}$. Also, suppose that for at least two consecutive periods $t$ and $t^{\prime}, \sigma_{k, t}(\cdot ; \cdot) \neq \sigma_{k, t^{\prime}}(\cdot ; \cdot)$ for $k \in A$.

(i) If the data distribution contains information on at least two consecutive periods and the discount factor $\beta$ is fixed, the per-period utility $u(\cdot, \cdot ; \cdot)$ is nonparametrically identified. Moreover, if $u(\cdot, \cdot ; \cdot)=$ $u_{T}(\cdot, \cdot ; \cdot)$ and one of the observed periods is the period of mortgage maturity $T$, then the discount factor is also identified.

(ii) If the data distribution contains information on at least three consecutive periods, then both the

\footnotetext{
${ }^{20}$ We omit discussion regarding identification of $u_{T}(\cdot, \cdot ; \cdot)$, as it is obvious that $u_{T}(\cdot, \cdot ; \cdot)$, in case $u_{T} \neq u$, is identified if and only if decisions from the final period are observed.
} 
discount factor and the per-period utility function $u(\cdot, \cdot ; \cdot)$ are identified.

This theorem, proved in the Appendix, establishes a general result that the considered model is identified (including identification of the time preference parameter) if the payoff from default is a known function. The argument requires us to find two time periods in which the optimal decision probability conditional on the state variables and the type varies across those periods. The theoretical justification for why two such periods exist stems from the finite horizon: Borrowers' tendency to default should depend upon the time remaining until the mortgage maturity date. In general, the optimal decision rules will depend on time $t$ in finite horizon models even conditional on the state variables, satisfying the assumption of the proposition. Unlike the prior literature on identification of time preferences (Magnac and Thesmar (2002); Fang and Wang (2012)), our identification of the discount factor does not require the presence of a variable that affects the state transition but not the per-period utility, because in finite-horizon models, the time to maturity itself plays a role analogous to that of such variables.

For cases in which the default utility is not a known function, we would need to normalize it. In the empirical literature on the dynamic discrete optimization problems, it has been noted (e.g., see Bajari, Hong and Nekipelov (2012)) that different normalizations of the per-period utility are not innocuous and can lead to different estimates of the differences between deterministic utility components of the normalized choice (default in our case) and the other choices. Moreover, in the finite-horizon optimal decision problem, the structural model is, under certain conditions, overidentified for a chosen normalization so that no normalization is necessary. These two insights can be used to explore the identification of the elements of the structural model, specifically the payoff from default. We formally show that in the finite-horizon optimal stopping problem, the normalization of the per-period payoff from the default choice to zero is not innocuous. ${ }^{21}$ Moreover, we show that under stronger requirements on the data, one can identify the payoff from the default option without the need to normalize any payoff.

Theorem 3 (Identification with normalized default utility) Suppose that the distribution of idiosyncratic shocks conditional on the borrower-specific heterogeneity variables $c, F_{\varepsilon}(\cdot \mid c)$, has a full support with the density strictly positive on $\mathbb{R}^{3}$. Also suppose that for at least two consecutive periods $t$ and $t^{\prime}$, $\sigma_{k, t}(\cdot ; \cdot) \neq \sigma_{k, t^{\prime}}(\cdot ; \cdot)$ for $k \in A$.

(i) If $u(\cdot, \cdot ; \cdot) \neq u_{T}(\cdot, \cdot ; \cdot)$ or the choices of the borrowers in the final period are not observed, the default utility $u(0, s ; c)$ is not identified. If in this case $u(0, s ; c)$ is normalized to a fixed function, the recovered discount factor does not depend on the choice of normalization for the default utility.

\footnotetext{
${ }^{21}$ We are grateful to Günter Hitsch, who encouraged us to present the formal argument supporting this statement.
} 
However, the recovered differences between the per-period payoffs from payment or prepayment and the per-period payoff from default depend upon the choice of normalization for the default utility.

(ii) Suppose that $u(\cdot, \cdot ; \cdot)=u_{T}(\cdot, \cdot ; \cdot)$ and that the choices of the borrowers in the period of mortgage maturity $T$ are observed along with the choices from earlier periods. Then, the utilities from all choices, $u(0, s ; c), u(1, s ; c)$, and $u(2, s ; c)$, are identified along with the discount factor $\beta$.

The theorem, proved in the Appendix, has a clear interpretation. In the last period the decision of the borrower is static and thus there is no option of "delayed default." As a result, the last-period decision depends only on the differences between the utilities from the payment and prepayment options and the utility from the default option. However, in any period before the last, the borrower has an option of defaulting in the following period if he pays or prepays in the current period, but not if he defaults. This asymmetry implies that the normalization has a disproportional effect on the discounted payoffs from different options. Part (i) of the theorem holds because, while the utility from default in the current period is shifted by the normalization (as the future discounted payoff is zero), the payoffs from payment or prepayment are additionally shifted by the amount equal to the discounted expected payoff from defaulting in the next period. Nevertheless, $\beta$ is invariant to the normalization because the tradeoff between current payoffs and future option values is unaffected by the normalization.

Part (ii) of the theorem holds because if the final period choices were observed, they would allow us to pin down the actual levels of the payoffs and not just the differences. However, our data do not allow us to observe the behavior of the borrowers whose mortgages are close to maturity. Furthermore, the per-period payoff function in the final period is probably different from the per-period payoff function of earlier periods in our setup. As a result, to identify the model using our data we need to use part (i) and normalize the utility from default. We discuss our choice of normalization in more detail when we discuss estimation results.

In the following example, we derive closed-form expressions for components of the model after normalizing the default utility and making the type I extreme value assumption for the idiosyncratic shocks. In this case, the ex ante value function takes the form

$$
V_{t}\left(s_{i, t} ; c_{i}\right)=\log \left(\sum_{k=0}^{2} \exp \left(V_{t}\left(a_{i, t}=k, s_{i, t} ; c_{i}\right)\right)\right)=\log \left(\frac{1}{\sigma_{t}\left(0, s_{i, t} ; c_{i}\right)}\right)+u\left(0, s_{i, t} ; c_{i}\right),
$$

where $u(0, s ; c)$ is the normalized utility from default. We can then combine the expression for the ex ante value function with the expression for the Bellman equation for each of the non-default choices to 
obtain the following system of equations

$$
\begin{aligned}
\log \left(\frac{\sigma_{t}\left(k, s_{i, t} ; c_{i}\right)}{\sigma_{t}\left(0, s_{i, t} ; c_{i}\right)}\right) & =u\left(k, s_{i, t} ; c_{i}\right)-u\left(0, s_{i, t} ; c_{i}\right) \\
& +\beta E\left[\log \left(\frac{1}{\sigma_{t+1}\left(0, s_{i, t+1} ; c_{i}\right)}\right)+u\left(0, s_{i, t+1} ; c_{i}\right) \mid s_{i, t}, c_{i}, a_{i, t}=k\right], \quad k=1,2 .
\end{aligned}
$$

This system of equations can be written for each instant of time $t$. In particular, if the data contain at least three consecutive periods, the system of equations can be used to find the discount factor, which will be over-identified:

$$
\beta=\frac{\log \left(\frac{\sigma_{t+1}\left(k, \bar{s} ; c_{i}\right)}{\sigma_{t+1}\left(0, \bar{s} ; c_{i}\right)} \frac{\sigma_{t}\left(0, \bar{s} ; c_{i}\right)}{\sigma_{t}\left(k, \bar{s} ; c_{i}\right)}\right)}{E\left[\log \left(\sigma_{t+1}\left(0, s_{i, t+1} ; c_{i}\right)\right) \mid s_{i, t}=\bar{s}, c_{i}, a_{i, t}=k\right]-E\left[\log \left(\sigma_{t+2}\left(0, s_{i, t+2} ; c_{i}\right)\right) \mid s_{i, t+1}=\bar{s}, c_{i}, a_{i, t+1}=k\right]}
$$

for $k=1,2$. By the assumption of our Theorem 1, the denominator of this expression is not equal to zero. As a result, the discount factor is identified.

\section{Econometric Methodology}

\subsection{Semiparametric Estimator}

Our specification of borrowers' per-period payoffs is a version of the random coefficients model where the distribution of coefficients characterizes the borrower-level heterogeneity $c$. For notational simplicity, from now on we drop the index $i$ for borrowers, except where necessary for disambiguation. The per-period utility is parameterized by the random coefficients and we define it as

$$
u(a, s ; c)=u(s ; \theta(a, c))
$$

where $a \in A$ and $\theta: A \times \mathcal{C} \mapsto \Theta$, where $\Theta$ is the parameter space. We allow the utility to be nonparametric and the coefficient vector $\theta(a, c)$ may be considered the vector of coefficients for the sieve representation of the per-period payoff function. Such a representation of the per-period utility gives us the flexibility in choosing either a parametric or a fully nonparametric specification for the utility associated with each realization of the state variables, action, and borrower type. It also places our model in the class of dynamic discrete choice models in which the unobserved heterogeneity is modeled using mixture distributions (e.g., Kasahara and Shimotsu (2009) and Arcidiacono and Miller (2011)).

To estimate the model we use a plug-in semiparametric estimator. Parallel to our identification 
argument, we nonparametrically estimate the borrowers' policy functions and use them to recover the choice-specific value functions of the borrowers. We then use the latter to recover the distribution of random coefficients in the utility function and the time preference parameter. Below, we first characterize the general form of the estimator corresponding to an arbitrary distribution of idiosyncratic payoff shocks satisfying Assumption 1. Then we discuss our specific implementation, with idiosyncratic payoff shocks that are distributed type I extreme value. For this case, estimation reduces to evaluating several linear projections, which does not require costly computations and can be implemented using any software that is capable of estimating a linear regression. Estimation for more general shock distributions may require solving nonlinear equations and thus more advanced computational tools.

Step 1 First, we nonparametrically estimate the conditional choice probabilities of the borrowers. Our data represent a panel of $i=1, \ldots, J$ loans observed in periods $\tau=1, \ldots, T^{*}$ indexing calendar time. The panel is unbalanced due to defaults and issuance of new loans. By $T_{i, \tau}$ we denote the time elapsed (in months) from the period of mortgage origination for a loan $i$ observed in period $\tau$. We estimate the policy functions by evaluating the conditional distribution of observed actions, for each observed loan age $t$. In estimation we use the orthogonal series $q^{L}(\cdot)=\left(q_{1}(\cdot), \ldots, q_{L}(\cdot)\right)^{\prime}$, where $L$ is the number of series terms. We consider the orthogonal representation for the choice probability as

$$
\log \frac{\sigma_{t}(k, s ; c)}{\sigma_{t}(0, s ; c)}=\sum_{l=1}^{\infty} r_{l}(t, k, c) q_{l}(s), \text { for } k=1,2
$$

where $r_{l}(t, k, c)$ are coefficients of the series representation and $r^{L}(t, k, c)=\left(r_{1}(t, k, c), \ldots, r_{L}(t, k, c)\right)$. This representation will be uniformly accurate if the choice probability ratio is continuous and the state space $\mathcal{S}$ is a compact set, by the Weierstrass theorem. Then the estimator will be based on replacing the infinite sum with a finite sum for some (large) number $L$. The parameters are estimated by forming a quasi-likelihood:

$$
\begin{aligned}
\widehat{Q}\left(r^{L}(t, 1, c), r^{L}(t, 2, c) ; c\right)= & \frac{1}{J T^{*}} \sum_{\tau=1}^{T^{*}} \sum_{i=1}^{J} \mathbf{1}\left\{T_{i, \tau}=t\right\} \mathbf{1}\left\{c_{i}=c\right\}\left[\mathbf{1}\left\{a_{i, t}=1\right\} \sum_{l=1}^{L} r_{l}(t, 1, c) q_{l}\left(s_{i, t}\right)\right. \\
& +\mathbf{1}\left\{a_{i, t}=2\right\} \sum_{l=1}^{L} r_{l}(t, 2, c) q_{l}\left(s_{i, t}\right) \\
& \left.-\log \left(1+\exp \left(\sum_{l=1}^{L} r_{l}(t, 1, c) q_{l}\left(s_{i, t}\right)\right)+\exp \left(\sum_{l=1}^{L} r_{l}(t, 2, c) q_{l}\left(s_{i, t}\right)\right)\right)\right] .
\end{aligned}
$$

Then we obtain the estimator as

$$
\left(\widehat{r}^{L}(t, 1, c), \widehat{r}^{L}(t, 2, c)\right)=\operatorname{argmax}_{r} \widehat{Q}\left(r^{L}(t, 1, c), r^{L}(t, 2, c) ; c\right) .
$$


The estimated policy functions correspond to the fitted values based on the estimated parameters:

$$
\begin{aligned}
& \widehat{\sigma}_{t}(k, s ; c)=\frac{\exp \left(\sum_{l=1}^{L} \widehat{r}_{l}(t, k, c) q_{l}(s)\right)}{1+\exp \left(\sum_{l=1}^{L} \widehat{r}_{l}(t, 1, c) q_{l}(s)\right)+\exp \left(\sum_{l=1}^{L} \widehat{r}_{l}(t, 2, c) q_{l}(s)\right)} \text { for } k=1,2, \\
& \widehat{\sigma}_{t}(0, s ; c)=1-\widehat{\sigma}_{t}(1, s ; c)-\widehat{\sigma}_{t}(2, s ; c)
\end{aligned}
$$

The number of series terms will be a function of the total sample size, with $L \rightarrow \infty$ as $J T^{*} \rightarrow \infty .{ }^{22}$ As we show below, for our distribution results to be valid (and, thus, for the first-stage estimation error to have no impact on the convergence rate for the estimated structural parameters), it is sufficient to find an estimator for the choice probabilities with a uniform convergence rate of at least $\left(J T^{*}\right)^{1 / 4}$. Such estimators will exist if the choice probability is a sufficiently smooth function of the state.

Step 2 We consider an estimator for the structural parameters that is tailored to our data, which feature truncation of the observed sample of loans before they mature. In the case of an arbitrary distribution of idiosyncratic shocks, we must perform a functional inversion to recover the choice-specific and ex ante value functions from the estimated policy functions. Suppose that $F_{\varepsilon}(\cdot \mid c)$ is the distribution of payoff shocks (conditional on the "type" of the borrower) with density $f_{\varepsilon}(\cdot \mid c)$. Consider functions

$$
\begin{aligned}
& \sigma_{0}\left(z_{1}, z_{2} ; c\right)=\int_{\varepsilon_{0} \geq z_{1}+\varepsilon_{1}, \varepsilon_{0} \geq z_{2}+\varepsilon_{2}} f_{\varepsilon}(\varepsilon \mid c) d \varepsilon_{0} d \varepsilon_{1} d \varepsilon_{2}, \\
& \sigma_{1}\left(z_{1}, z_{2} ; c\right)=\int_{z_{1}+\varepsilon_{1} \geq \varepsilon_{0}, z_{1}+\varepsilon_{1} \geq z_{2}+\varepsilon_{2}} f_{\varepsilon}(\varepsilon \mid c) d \varepsilon_{0} d \varepsilon_{1} d \varepsilon_{2}, \\
& \sigma_{2}\left(z_{1}, z_{2} ; c\right)=\int_{z_{2}+\varepsilon_{2} \geq \varepsilon_{0}, z_{2}+\varepsilon_{2} \geq z_{1}+\varepsilon_{1}} f_{\varepsilon}(\varepsilon \mid c) d \varepsilon_{0} d \varepsilon_{1} d \varepsilon_{2} .
\end{aligned}
$$

In Lemma 1 in the Appendix, we show that these functions are well-defined and that if the default probability is strictly between zero and one for almost all values of the state variables, the system determining the choice probabilities is everywhere invertible for $z_{1}, z_{2} \in \mathbb{R}$, assuming a large support of the idiosyncratic payoff shocks. We can use the above system of equations to recover the differences between the choice-specific value of a non-default choice and the utility from default in each period for each value of the state variables $s$ and each point in the support of borrower-specific heterogeneity $c$.

To see this, we reexpress the choice probabilities as functions of these differences, equate them to their empirical analogues (which were recovered in the first step), and drop the expression for action 2

\footnotetext{
${ }^{22}$ We provide precise prescription for the choice of the number of series terms in the theoretical part of this section.
} 
(because there are only two degrees of freedom). This yields

$$
\begin{aligned}
& \widehat{\sigma}_{0, t}(s ; c)=\sigma_{0}\left(V_{t}(1, s ; c)-u(s ; \theta(0, c)), V_{t}(2, s ; c)-u(s ; \theta(0, c)) ; c\right), \\
& \widehat{\sigma}_{1, t}(s ; c)=\sigma_{1}\left(V_{t}(1, s ; c)-u(s ; \theta(0, c)), V_{t}(2, s ; c)-u(s ; \theta(0, c)) ; c\right) .
\end{aligned}
$$

The solution to the above system (as a function of the state and the borrower type) can be expressed as:

$$
\widehat{V}_{t}(k, s ; c)=u(s ; \theta(0, c))+F_{k}\left(\widehat{\sigma}_{0, t}(s ; c), \widehat{\sigma}_{1, t}(s ; c)\right), k=1,2
$$

where function $F_{k}(\cdot, \cdot)$ is the solution of the inversion problem (4) for the argument $z_{k}$. We can characterize the ex ante value function as

$$
\widehat{V}_{t}(s ; c)=u(s ; \theta(0, c))+F\left(\widehat{\sigma}_{0, t}(s ; c), \widehat{\sigma}_{1, t}(s ; c)\right)
$$

where the function $F(\cdot, \cdot)$ is determined by the solutions $F_{1}(\cdot, \cdot)$ and $F_{2}(\cdot, \cdot)$ and the distribution of the idiosyncratic payoff shocks.

Then we substitute the obtained expressions into the Bellman equation for the borrower. We obtain a system of nonlinear simultaneous equations

$$
\begin{aligned}
E\left[F_{k}\left(\sigma_{0, t}\left(s_{t} ; c\right), \sigma_{1, t}\left(s_{t} ; c\right)\right)\right. & -u\left(s_{t} ; \theta(k, c)\right)+u\left(s_{t} ; \theta(0, c)\right)-\beta u\left(s_{t+1} ; \theta(0, c)\right) \\
& \left.-\beta F\left(\sigma_{0, t+1}\left(s_{t+1} ; c\right), \sigma_{1, t+1}\left(s_{t+1} ; c\right)\right) \mid a_{t}=k, s_{t}, c\right]=0, \quad k=1,2
\end{aligned}
$$

where the current state $s_{t}$, the current action, and the borrower type serve as instruments. ${ }^{23}$ This system can be estimated directly by substituting in the state at time $t, s_{t}$, and treating $F_{1}$ and $F_{2}$ as the "outcome variables" (i.e., functions of $s_{t}$ ), with the right-hand side containing the parameters to be estimated (i.e., the unknown utilities parameterized by $\theta(a, c)$ and the time preference parameter $\beta)$. Alternatively, we can estimate this system using a nonlinear IV methodology. For estimation, it is convenient to replace this system of conditional moment equations with a system of unconditional moment equations, using the set of instruments $Z_{t}=\left\{W_{m}\left(s_{t} ; c\right), m \in \mathcal{M}\right\}$. $Z_{t}$ is constructed from the current state variables, the current action, and borrower-level heterogeneity elements $c$ using functions from some set $\mathcal{M}$, which

\footnotetext{
${ }^{23}$ In our empirical application, we choose a normalization of default utility such that it is a function of some time-invariant state variables that affect default utility only and not the per-period utility of prepayment or payment. This allows us to identify $\theta(0, c)$ separately from $\theta(1, c)$ and $\theta(2, c)$. One might choose a different normalization in other settings, but as discussed in the previous section, we need a normalization of some kind in order to identify the model.
} 
could be a finite list of orthogonal polynomials of the state variables. Denote

$$
\begin{gathered}
\epsilon_{k t}=F_{k}\left(\sigma_{0, t}\left(s_{t} ; c\right), \sigma_{1, t}\left(s_{t} ; c\right)\right)-u\left(s_{t} ; \theta(k, c)\right)+u\left(s_{t} ; \theta(0, c)\right)-\beta u\left(s_{t+1} ; \theta(0, c)\right) \\
-\beta F\left(\sigma_{0, t+1}\left(s_{t+1} ; c\right), \sigma_{1, t+1}\left(s_{t+1} ; c\right)\right), \quad k=1,2
\end{gathered}
$$

Define $\epsilon_{t}=\left(\epsilon_{1 t}, \epsilon_{2 t}\right)^{\prime}$ and $Z_{t}=\left(Z_{1 t}, Z_{2 t}\right)$. Then the system of unconditional moment equations takes the familiar form

$$
E\left[\epsilon_{t} Z_{t}\right]=0
$$

Provided that the model that we analyze is smooth with respect to the nonparametrically estimated components, such as choice probabilities, we can apply the results in Chen, Linton, and van Keilegom (2003) and Mammen, Rothe, and Schienle (2012) to establish the impact of the first-stage estimation error on the standard errors of the structural estimates. In the next section, we will analyze the properties of this two-step estimator for the case of a general distribution of the idiosyncratic payoff shocks.

When the idiosyncratic payoff shocks have an i.i.d. type I extreme value distribution, the elements of the derived system of conditional moment equations can be expressed in closed form:

$$
F\left(\sigma_{0}(s ; c), \sigma_{1}(s ; c)\right)=\log \left(\sigma_{0}(s ; c)^{-1}\right)
$$

And the functions $F_{1}(\cdot)$ and $F_{2}(\cdot)$ in this case take the form:

$$
F_{k}\left(\sigma_{0}(s ; c), \sigma_{1}(s ; c)\right)=\log \left(\sigma_{k}(s ; c) / \sigma_{0}(s ; c)\right), \text { for } k=1,2
$$

The choice-specific and ex ante value functions in this case can be recovered directly from the estimated choice probabilities (up to normalization $u(s ; \theta(0, c))$ ), without requiring any iterations or complicated inversions. The per-period payoffs are then recovered from the second-stage plug-in estimator, using the recovered choice-specific and ex ante value functions as inputs.

Thus, when the choice utilities are linearly parameterized and in addition we assume type I extreme value distribution for the idiosyncratic payoff shocks, the second stage estimates can be obtained using standard least squares, which does not even require the construction of the GMM objective function, and our entire estimation procedure reduces to performing three linear regressions:

1. We nonparametrically estimate the borrower's choice probabilities $\sigma_{k, t}(\cdot ; c)$. Using these choice probabilities we recover the ex ante value function for each borrower in each time period, constructing the variable $F_{i, t}=\log \left(\widehat{\sigma}_{0}\left(s_{i, t} ; c_{i}\right)^{-1}\right)$. 
2. We estimate the one-period-ahead expected ex ante value $E\left[F\left(\sigma_{0, t+1}\left(s_{t+1} ; c\right), \sigma_{1, t+1}\left(s_{t+1} ; c\right)\right) \mid a_{t}, s_{t}, c\right]$ by estimating a nonparametric regression of variable $F_{i, t+1}$ constructed in the first step on $a_{i, t}, s_{i, t}$ and $c_{i}$ for each borrower. The fitted values from this regression form variable

$$
\widetilde{F}_{k, i, t+1}=\widehat{E}\left[F\left(\sigma_{0, t+1}\left(s_{i, t+1} ; c_{i}\right), \sigma_{1, t+1}\left(s_{i, t+1} ; c_{i}\right)\right) \mid a_{i, t}=k, s_{i, t}, c_{i}\right] \text { for } k=1,2
$$

which is constructed for each borrower in each time period.

3. We construct the "outcome" variables $Y_{k, i, t}=\log \left(\hat{\sigma}_{k, t}\left(s_{i, t} ; c_{i}\right) / \hat{\sigma}_{0, t}\left(s_{i, t} ; c_{i}\right)\right)$ for $k=1,2$. Assuming that the per-period utility is represented by a linear index of the state variables, we construct a vector of "regressors"

$$
X_{k, i, t}=\left(s_{i, t},-s_{i, t}+\beta \widehat{E}\left[s_{i, t+1} \mid s_{i, t}, a_{t}=k\right], \widetilde{F}_{k, i, t+1}\right)^{\prime}
$$

The components of this vector correspond to $u\left(s_{t}, \theta(k, c)\right),-u\left(s_{t}, \theta(0, c)\right)+\beta u\left(s_{t+1}, \theta(0, c)\right)$ and $F\left(\sigma_{0, t+1}\left(s_{t+1} ; c\right), \sigma_{1, t+1}\left(s_{t+1} ; c\right)\right)$, respectively. Then estimating coefficient $\delta_{k}$ in linear regression

$$
Y_{k, i, t}=\delta_{k}^{\prime} X_{k, i, t}+\epsilon_{k, i, t}
$$

yields the structural parameters of interest. In fact, by construction of $Y$ and $X$ we get $\delta_{k}=$ $(\theta(k, c), \theta(0, c), \beta)^{\prime}$. We can further improve inference by combining models for $k=1,2$ into a system of linear equations.

The simplicity of our approach is attractive for practical reasons, and our approach also has other advantages relative to many existing techniques for estimating structural decision models. First, our approach does not require making predictions of borrowers' decisions far into the future. Instead, we exploit Hotz and Miller's (1993) intuition that, in the presence of a terminating action, one can represent the value function as a function of one-period-ahead choice probabilities. This property is particularly useful in contexts like ours that feature heavy data truncation. Second, our estimation uses projection instead of simulations to compute the one-period-ahead ex ante value function. Projection methods are computationally more attractive than simulations.

It is also worthwhile to note that we recover agents' expectations nonparametrically in step 2. Incorporating this nonparametrically estimated expectation into the model is closely related to work in Ahn and Manski (1993). 


\subsection{Asymptotic Theory for the Plug-In Estimator}

The previous section outlined the structure of the two-step plug-in estimator for the structural parameters, which include the per-period payoffs and the discount factor. This section provides the asymptotic theory for the constructed estimator. We assume a parametric specification for the per-period utility, although our theory allows for an immediate extension to a nonparametric specification of the per-period utility. A key requirement of the plug-in semiparametric procedure is that the first-stage nonparametric estimator of the policy functions converge at a sufficiently fast rate. Our results for the consistency and the convergence rate of the first-stage estimator rely on the results in Wong and Shen (1995), Andrews (1991) and Newey (1997).

To assure consistency and fast convergence rate for the first-stage estimator, we need the following assumption.

\section{ASSUMPTION 2}

1. For each period the distribution of observed actions and states $\left(a_{i, t}, s_{i, t}\right) \mid\left(s_{i, t-1}, c_{i}\right)$ is i.i.d. across the borrowers conditional on borrower heterogeneity $c_{i}$, and the choice probabilities $\sigma_{k, t}(\cdot ; c)$ are uniformly bounded from 0 and 1 for each $k=0,1,2$ and $c \in \mathcal{C}$. The state space $\mathcal{S}$ is compact.

2. The eigenvalues of $E\left[q^{L}\left(s_{i, t}\right) q^{L \prime}\left(s_{i, t}\right) \mid a_{i, t}, c_{i}\right]$ are bounded away from zero uniformly over $L$, and $\left|q_{l}(\cdot)\right| \leq C$ for all $l$.

3. $\frac{\sigma_{k, t}(s ; c)}{\sigma_{0, t}(s ; c)}$ belongs to a separable functional space with basis $\left\{q_{l}(\cdot)\right\}_{l=1}^{\infty}$. For each $t \leq T$ and $k \in\{1,2\}$ the selected series terms provide a uniformly good approximation for the probability ratio

$$
\sup _{s \in \mathcal{S}}\left\|\log \frac{\sigma_{k, t}(s ; c)}{\sigma_{0, t}(s ; c)}-\operatorname{proj}\left(\log \frac{\sigma_{k, t}(s ; c)}{\sigma_{0, t}(s ; c)} \mid q^{L}(\cdot)\right)\right\|=O\left(L^{-\alpha}\right)
$$

for some $\alpha \geq \frac{1}{2}$

4. Conditional choice probabilities are twice differentiable uniformly in the observed heterogeneity component $c$.

Assumption 2 can be verified for particular classes of polynomials and sieves in Chen (2007). We also impose an additional assumption restricting the complexity of the class of functions that is associated with "nonparametric multinomial logit" estimator that we constructed, and discuss this in the Appendix. Using these assumptions, we can provide the following result establishing the consistency and convergence rate of the first-stage estimator for the policy functions. ${ }^{24}$

\footnotetext{
${ }^{24}$ Proof is in the Appendix.
} 
Theorem 4 Under Assumptions 1 and 2, the estimator (3) is consistent uniformly over s:

$$
\sup _{s \in \mathcal{S}}\left\|\widehat{\sigma}_{k, t}(s \mid c)-\sigma_{k, t}(s \mid c)\right\|=o_{P}\left(\left(J T^{*}\right)^{-1 / 4}\right)
$$

provided that $\frac{J T^{*}}{L \log \left(J T^{*}\right)} \rightarrow \infty$ as $J T^{*} \rightarrow \infty$.

The first-stage policy function estimates are used for welfare evaluations and benchmark comparisons. We also use the estimated first-stage policy functions as inputs for the estimation of the second-stage structural parameters. Our approach is based on application of the existing plug-in techniques for implementation of estimator (5). These techniques use pre-estimated nonparametric elements of the statistical model (in our case, the policy functions) that are plugged into a fully parametric second step. A common approach of semiparametric plug-in estimation is to use a weighted minimum distance procedure, where the weights are chosen optimally to maximize the efficiency of the resulting estimator. We use the vector of state variables and the nonparametric estimates for the one-period-ahead ex ante value function (which can be easily constructed using the first-stage policy function estimates) as instruments, using the identity matrix as the weight matrix. Although this estimator is not semiparametrically efficient, it has the advantage of being estimable using least squares rather than requiring GMM.

To establish the asymptotic properties of the designed procedure we impose the following assumptions.

\section{ASSUMPTION 3}

1. Parameter space $\Theta$ is a compact subset of $\mathbb{R}^{p}$.

2. The per-period payoff is Lipschitz-continuous in parameters.

3. The variance of the one-period-ahead policy function is bounded $\left(\sup _{s \in \mathcal{S}} E\left[\sigma_{k, t+1}\left(s_{t+1} ; c\right)^{2} \mid s_{t}=s\right]<\right.$ $\infty)$ and strictly positive $\left(\inf _{s \in \mathcal{S}} E\left[\sigma_{k, t+1}\left(s_{t+1} ; c\right)^{2} \mid s_{t}=s\right]>0\right)$ for any $t<T$.

Under this assumption and the technical assumption regarding the complexity of the class of functions containing the estimated first-stage policy functions, we can use the results regarding semiparametric plug-in estimators in Ai and Chen (2003) and Chen, Linton and van Keilegom (2003), and establish the following result for the estimator for the second-stage structural parameters.

Theorem 5 Under Assumptions 1, 2 and 3, the estimator (5) is consistent and has asymptotic normal distribution:

$$
\sqrt{J T^{*}}\left((\widehat{\theta(a, c)}, \hat{\beta})-\left(\theta_{0}(a, c), \beta\right)\right) \stackrel{d}{\longrightarrow} N(0, V)
$$


where variance $V$ is determined by the functional structure of the model.

The result of this theorem follows from Theorem 4.1 in Ai and Chen (2003). A significant difference between equations (5) used for our estimation and the conditional moment equations implied by infinitehorizon Markov dynamic decision processes is that the one-period-ahead values in our moment equations are estimated separately. As a result, the estimated choice-specific value function and the one-periodahead ex ante value function can be considered unrelated nonparametric objects (in contrast to infinitehorizon dynamics, where the two are connected via a fixed point). This facilitates the evaluation of the asymptotic variance. We give explicit expression for the variance in the Appendix.

\section{Estimation Results}

\subsection{Main Results}

Our baseline specification has a fixed coefficient design, assuming that heterogeneity across borrowers is fully captured by the state vector $s$ (equivalent to assuming that the set of observable borrower types $\mathcal{C}$ is a singleton). In our analysis of alternative specifications later in this section, we will relax this assumption by considering a random coefficient design in which borrower $i$ 's type, $c_{i}$, is defined by some observable time-invariant characteristics that are not part of the state vector. In our analysis of alternative specifications, we also consider the possibility of time-varying unobserved heterogeneity. In this subsection, we focus on the baseline specification.

\subsubsection{Results on Policy Function Estimates}

We start by discussing the first-step estimates of the policy functions. Because the policy function estimates are reduced-form in nature, the estimates themselves do not have well-defined economic interpretations. Thus, we focus on the goodness of fit of the policy function estimates instead of discussing the coefficients. Having policy function estimates that do a reasonable job of matching empirical probabilities is crucial for the reliability of the structural parameter estimates as well as the plausibility of the counterfactual results. We investigate the performance of our policy function estimates in three ways. First, we report the within-sample fit of our estimates using the full sample, comparing the predicted probabilities

of default, prepayment and payment in each period to the empirical counterparts. Second, we report the out-of-sample fit: we use half of the sample for estimation, use these estimates to compute the fitted probabilities in each period for the other half of the sample (the validation sample) and compare the 
fitted values to the empirical counterparts in the validation sample. Third, for each loan in the data, we start with the observed state as of the period in which the loan is first observed, and forward-simulate the borrower's decisions until the end of 2009 (the censoring date) using the estimated policy functions and state transitions. We then compare the predicted probability of eventual default or prepayment by the censoring date to the empirical counterparts. The fit implied by the first two methods depends on the precision of policy function estimates only (since we use the realized values of the state variables in each period in computing the predicted probabilities), whereas the fit in the third method depends on the precision of both the policy function estimates and the state transition estimates. More noise is introduced in the third method, so the fit is necessarily worse.

We use a sieve logit with splines of the state variables in order to flexibly model borrowers' choice probabilities. The state variables are the set of variables listed in Table 1 (excluding "owner-occupiers" and "purchase loans," which will be used to define borrower types later in the analysis of alternative specifications) as well as dummies for origination year and MSA. The sieve basis includes restricted cubic splines for continuous state variables, interpolating between 3 to 5 equally spaced percentiles of each state variable's marginal distribution. It also includes interactions among the state variables. To capture the dependence of the optimal choice probabilities on time to maturity $(T-t)$ where $T$ is fixed at 360 in our estimation sample, we also include 5 splines of $t$ and interact them with the other state variables.

To model transitions of home prices and the unemployment rate, we assume that the home price growth rate (in percentage terms) and the first difference of the unemployment rate follow $\mathrm{AR}(2)$ processes. Accordingly, we include the first and second lags of the original variables as well as their current values in the state vector of time period $t$, as the lags will be used by borrowers in forming expectations about their future values, which should influence borrowers' optimal choice in the current period. Similarly, we model the first difference of the market interest rate as an $\operatorname{AR}(1)$ process, and include the current value and the first lag of the market interest rate in the state vector.

Table 5 shows the within-sample fit, both overall and for various subgroups. The table shows that the within-sample fit of the first-step policy function estimates is excellent. The likelihood ratio index, also called McFadden's pseudo $\mathrm{R}^{2}$, is 0.153 , a significant improvement over a constant-only model.

[Table 5 about here]

Because we included very flexible splines of the state variables in estimation of the policy functions, one might worry about overfitting, leading to poor out-of-sample predictions. To check for this possibility, we randomly split our sample into two halves, and use the first half for estimation and second for validation. The fit for the validation sample is reported in Table 6 . 
[Table 6 about here]

Table 6 shows that the fit is excellent even in the validation sample, though it is unsurprisingly slightly worse than the within-sample fit in Table 5. Tables 5 and 6 demonstrate that the first-step estimates predict borrowers' observed behavior accurately, but another critical piece that will play an important role in counterfactual simulations is the accuracy of the estimated state transitions. To evaluate the combined fit of the estimated policy functions and transition functions, we start with the earliest observation for each borrower, simulate the sequence of state transitions and borrower's actions using the estimated policy functions and transition functions, and then compare the simulated path with the actual data. Table 7 compares the observed paths with the predicted paths in terms of the probability of eventual default or prepayment by the end of 2009 (the censoring date) as well as the duration until default or prepayment.

[Table 7 about here]

The table again shows comparisons for the overall sample as well as various slices of the sample. Clearly, the fit is not as good as in the previous tables due to the additional noise introduced by estimation error in the state transitions. However, we still find that the first-step estimates explain the data very well.

\subsubsection{Results on Projection of One-Period-Ahead Ex Ante Value Function}

Once we recover the policy functions in the first stage, we can compute the ex ante value up to the normalization $u(0, s ; c)$ for each observation in the data using (1) under the assumption of type I extreme value payoff shocks. To estimate the expected ex ante value one period ahead, at time $t+1$, as a function of state variables and the chosen action at time $t$, we use a series estimator similar to that used to estimate the first-stage policy functions. As in Section 5.1.1, we use splines of state variables and interactions among them in the estimation. We allow our prediction of the expected one-period-ahead ex ante value to depend upon time to maturity, to reflect the nonstationarity of the problem. This procedure allows

us to estimate $\widetilde{F}_{k, i, t+1}$ in (7) using a linear projection. Note that the one-period-ahead ex ante value in case of default is trivially equal to zero for all $t$ since default is a terminal action.

Our projection estimates, not reported but available upon request, explain an extremely high fraction of variation for the observed ex ante values, with $R^{2}$ around 0.92 . Our projection method is conceptually similar to an alternative approach that computes the next period's ex ante value using forward simulation based on the estimated state transition functions. We initially tried forward-simulation approach, but abandoned it in favor of the projection method, which is computationally much faster. 
Once we construct the expected ex ante value functions using the projection method, we have all the components of the borrower's Bellman equation, and are ready to estimate the structural parameters.

\subsubsection{Results on Structural Estimates}

Following the estimation procedure outlined in Section 4.1, we estimate the structural parameters of the per-period utility as well as the discount factor. As discussed in our model section, we must normalize the utility of default. Because the normalization is not innocuous (Theorem 3), we must choose a normalization that reasonably reflects the economic conditions of borrowers. We assume that a borrower's utility from default - or equivalently, the cost of default - depends upon the borrower's credit score at the time of mortgage origination, because the cost of damaged credit in case of default conceivably depends upon the borrower's existing credit quality. Furthermore, we assume that the location of the borrower's residence also influences the default utility, because mortgages are recourse loans in some states but non-recourse loans in other states. Under non-recourse, lenders cannot go after a defaulter's assets other than the mortgage collateral (i.e., the house), which lowers the perceived cost of default to the borrower. Because the FICO score and state of residence plausibly do not have a direct impact on the utility from payment or prepayment, we include these variables in the utility function of default only. ${ }^{25}$

For estimation we use model (7) for $k=1,2$ and impose the cross-equation restriction that the parameters in the default payoff-parameters on FICO and MSA dummies - should be the same in both the payment equation and the prepayment equation. We also impose two additional cross-equation restrictions constraining the discount factor and the degree of disutility from the monthly payments to be the same in the prepayment and payment equations. We parameterize the utility functions to be linear in the parameters and state variables (including the monthly payments). In effect, we assume that borrowers are risk-neutral. We estimate system (7) for $k=1,2$ using a standard seemingly unrelated regression (SUR). Table 8 reports our estimates of the structural parameters.

[Table 8 about here]

Our results for the per-period payoff from default and per-period payoff from paying are sensible. Borrowers with higher FICO scores have a lower utility of default, consistent with default resulting in a higher cost of damaged credit for borrowers with good existing credit. Higher home value and lower monthly payments increase the utility of continuing to pay. Higher local unemployment, a proxy for the likelihood of job loss by the borrower, reduces the utility of continuing to pay. Borrowers with lowdocumentation ("low-doc") loans, who are presumably riskier, have lower utility from paying. These

\footnotetext{
${ }^{25}$ We will later briefly discuss how sensitive our results are to a different normalization.
} 
indicators of greater borrower risk may proxy for a higher probability of binding liquidity constraints, which effectively raises the cost of making the monthly payments and thus decreases the probability of choosing the "pay" option.

The intuition for the prepayment equation estimates is somewhat more nuanced. Importantly, the probability of prepayment depends on both the borrowers' willingness to refinance and their ability to do so. In particular, borrowers may be unable to refinance if they are deemed to be too risky at the time of refinancing. This is consistent with coefficient estimates, which imply that higher house value (which increases the borrower's equity) and lower local unemployment increase the propensity to prepay.

Moreover, the coefficients may be determined in part by unobserved heterogeneity in borrower or loan characteristics. While this is true as well of the "pay" equation, unobserved heterogeneity seems even more important in the case of prepayment, because households have many idiosyncratic reasons for wanting to prepay. For example, the positive coefficient on "Multiple Liens" makes sense if borrowers generally take out multiple liens only as a temporary measure and intend to consolidate their loans through refinancing relatively quickly. ${ }^{26}$ Finally, although we limit our attention to 30-year fixed-rate mortgages, we cannot rule out unobserved loan characteristics (e.g., stringency of prepayment conditions) that may be correlated with some of the state variables. For example, the coefficient on the prepayment penalty parameter is positive, which seems initially surprising, as one might expect prepayment penalties to decrease the utility of refinancing. However, consumers who were unsophisticated enough to obtain loans with prepayment penalty likely obtained a loan that was also unattractive on other dimensions (unobserved to econometricians), and accordingly might be more willing to refinance.

Finally, our estimate of 0.9815 for the monthly discount factor is just below one, as one might expect, and is statistically significantly different from 1 at $1 \%$ level. There is nothing in the model that restricts the estimate of the discount factor, so it is very reassuring to see that our estimated discount factor is a plausible number.

\subsection{Alternative Specifications}

As noted previously, unobserved heterogeneity in borrowers' preferences is a potential concern. Certain kinds of unobserved heterogeneity may be borrower-specific, such as differences across individuals in their degree of aversion to defaulting. Other sources of unobserved heterogeneity may vary both across borrowers and over the duration of each loan. For example, because we only observe income at the

\footnotetext{
${ }^{26}$ We are unable to link our observations - which are all first liens - to subordinate liens by the same borrower. Subordinate liens typically have a higher interest rate, and a borrower might take out a second lien if their total borrowing requirements are over the GSE-conforming thresholds.
} 
beginning of the loan, income volatility over time (such as due to loss of employment) would manifest itself as unobserved variation over time in the borrower's ability to make monthly payments.

The importance of incorporating unobserved heterogeneity has been well understood since the early work by Heckman and Singer (1984). Recent literature has demonstrated the possibility of extending the random effects framework of Heckman and Singer (1984) to nonlinear dynamic models. In particular, Shum and $\mathrm{Hu}$ (2012) show that models with unobserved heterogeneity can be identified even when the unobserved shocks are serially correlated.

However, these results do not imply that estimators for structural parameters in models with unobserved heterogeneity are always guaranteed to exist or perform well. Moreover, Khan and Nekipelov (2011) show that in many parametric discrete-choice and game-theoretic models with unobserved heterogeneity, the Fisher information for structural parameters is zero. In other words, the shape of the likelihood function in the vicinity of the true parameter value is nearly flat, leading to irregular identification of those parameters. ${ }^{27}$ The specific implication of these findings to our model is that the identification is not robust to specific assumptions about the distribution of unobserved heterogeneity, unless there are observables that can credibly be excluded from the structural equations that shift the distribution of the heterogeneity. Intuitively, without such exclusion restrictions, identification is mostly driven by extreme realizations of unobserved heterogeneity (such that the decision to pay, prepay or default is almost predetermined even prior to including the covariates), meaning that the tail behavior of unobserved heterogeneity has a large effect on the estimates. ${ }^{28}$ Although unobserved heterogeneity is formally identified in many settings similar to ours, the above features have been underappreciated in the literature.

Given that this non-robustness of the discrete choice model with unobserved heterogeneity in the absence of a reliable exclusion restriction is a fundamental problem, we propose to explore some alternative specifications of our model instead of attempting to estimate the distribution of unobserved heterogeneity. Our key goal is to explore whether the structural estimates remain interpretable under these alternative specifications. Fortunately, given that the likelihood function is nearly flat in irregularly identified models, potential differences in the obtained structural estimates have little effect on predictions made on the basis of the model.

Our first of two alternative specifications is a mixture model design in which borrowers have heterogeneous types that are determined entirely by observables. The second alternative specification incorporates

\footnotetext{
${ }^{27}$ In other words, the estimators have non-Gaussian asymptotic distributions and do not converge at a parametric rate.

${ }^{28}$ Moreover, Khan and Nekipelov (2012) show that possible approaches to making the estimates more robust, such as trimming the support of the distribution of unobserved heterogeneity or restricting the class of possible distributions, are infeasible because they require a priori knowledge of the structure of underlying distributions such as their tail behavior.
} 
liquidity shocks, a plausible source of unobserved heterogeneity, by imposing a parametric distributional assumption on the probability of a liquidity constraint binding at a certain month after origination. We explain the logic behind each approach and discuss the results.

The mixture model design assumes that outcomes are determined by a mixture distribution, with heterogeneous borrower types that are determined by the observable, borrower-specific variables $c$. (Recall that $c$ is excluded from the vector of payoff-relevant state variables). For instance, the observable type of a borrower could be defined by whether the borrower intends to reside in the house or not (i.e., owneroccupiers versus investors). One might think that owner-occupiers have a stronger emotional attachment to the house than investors, and thus have a greater aversion to defaulting, all else equal. Therefore, the parameters of the utility function could vary between owner-occupiers and investors. Clearly, this approach does not directly address unobserved heterogeneity, but captures the component of unobserved heterogeneity that is correlated with the observable types. This approach is similar to the panel data model where fixed effects are represented by an unknown function (which is the same for all cross-sectional units) of included covariates.

We split the data into different borrower "types" based on owner-occupier status and loan purpose (home purchase versus refinancing). The estimates for the various observable types of borrowers are reported in Table 9.

[Table 9 about here]

Table 9 reveals interesting patterns about how utility functions might differ across different types of borrowers. For instance, the coefficient on the monthly payment variable is negative and statistically significant in the utility function of borrowers whose loans are for home purchases, but is not significantly different from zero in the utility function of borrowers whose mortgages are refinancing loans. This suggests that the level of monthly payments is an important factor in default decisions for borrowers who are still paying down on their original mortgages, but not so for borrowers who obtained a refinancing mortgage, probably because the payment level has been already reduced to a more manageable level when the borrowers refinanced their mortgages.

We also see that investors tend to be more sensitive to financial incentives in making their default decisions than owner-occupiers are, as evidenced by the larger magnitudes of the coefficients on house value and payment. This might reflect the fact that investors are more ruthless in default decisions than owner-occupiers are because of owner-occupiers' emotional attachment to their homes as well as the difficulty of moving out of the house in case of default. On the other hand, coefficients on some variables proxying for borrower riskiness - such as FICO scores, unemployment rate, income, and low 
documentation - are larger for owner-occupiers than for investors, presumably indicating that defaults driven by liquidity shocks are more common for owner-occupiers than for investors, who likely have more resources available.

In our second alternative specification, we attempt to control for the effects of liquidity shocks, an important source of unobserved heterogeneity, through parametric assumptions. A sufficiently large negative liquidity shock might force a borrower to default regardless of his strategic incentives. We can think of the borrower as facing a binding liquidity constraint at some random point in time over the course of the loan. We model the realization of this random time as being drawn from an exogenous distribution, and then adjust the choice-specific value functions to reflect the fact that default may be driven by either the borrower's strategic incentives, as modeled in our base specification, or by this liquidity constraint.

We assume that the liquidity shocks are orthogonal to the payoff shocks. From a formal perspective, this assumption is necessary for identification. From a conceptual viewpoint, this requires the borrowers to base their default decisions only on the present discounted value of the mortgage (as opposed to expectations about future liquidity shocks) as long as an unobserved liquidity constraint is currently nonbinding. Default may occur because of either "strategic" incentives — as outlined by our main modelor a negative liquidity shock, e.g., loss of job. This structure leads to a mixed hitting time model, studied in Abbring (2012).

We characterize liquidity-based default as follows. Each borrower $i$ is assumed to have a fixed default risk $\rho_{i}$, which characterizes the unconditional probability of the borrower defaulting due to liquidity shocks in a given period. The probability that this borrower does not default due to liquidity shocks before period $t$ of the loan is $\left(1-\rho_{i}\right)^{t-1}$. Assuming that the borrowers are atomic and that the conditional distribution of $\rho_{i}$ for a borrower of type $c_{i}$ is $f\left(\rho_{i} \mid c_{i}\right)$, the aggregate probability of illiquidity-driven default at a loan age of $t$, conditional on $c_{i}$ and conditional on survival to $t$, is

$$
P_{t}^{L}\left(c_{i}\right)=\frac{\int \rho(1-\rho)^{t-1} f\left(\rho \mid c_{i}\right) d \rho}{\int(1-\rho)^{t-1} f\left(\rho \mid c_{i}\right) d \rho} .
$$

Then if $f\left(\rho \mid c_{i}\right)$ follows a Beta distribution, $P_{t}^{L}\left(c_{i}\right)$ will have a binomial form in $t$ which can further be approximated by the Poisson distribution with argument $t$.

Our approach to the empirical analysis of the mixed hitting time model is based on the following observation regarding the behavior of strategic default probabilities $\sigma_{0, t}(s ; c)$.

LEMMA 2 Under Assumption 1, if the density of the distribution of choice-specific shocks has at least exponential tails and the utility function is strictly monotone in at least one of the state variables, then there exist constants $A_{1}$ and $A_{2}>0$, and $B_{1}$ and $B_{2}>0$ such that $A_{1} t^{-A_{2}}<\sigma_{0, t}(s ; c)<B_{1} t^{-B_{2}}$. 
This lemma establishes that the probability of strategic default declines at the geometric rate as the mortgage approaches maturity. This is due to the fact that with the finite planning horizon, the benefits of defaulting decline over time. On the other hand, we assumed that the probability of illiquidity-driven default declines at the exponential rate as the mortgage approaches maturity. This means that, starting at some period after mortgage origination, the probability of default will be dominated by the strategic default probability.

To incorporate this result into our estimation procedure, we use a parametric approach. In particular, we make an explicit assumption that the reduced-form liquidity-based default probability $P^{L}\left(\tau_{i, L}=t \mid c_{i}\right)$ is well approximated by the Poisson distribution, where $\tau_{i, L}$ is the instant of time when borrower $i$ defaults due to binding liquidity constraint. Based on the result from Lemma 2, the strategic default probability is monotone decreasing for fixed values of the state variables and for a particular borrower type, given Assumption 1. Therefore if the estimated default probability $P_{t}^{d}(s ; c)$, which is inclusive of both strategic default and illiquidity-driven default, is not monotone over $t$ for fixed $s$ and $c$, then the nonmonotonicity necessarily reflects the impact of illiquidity-driven default. In particular, we can recover the function $\hat{\lambda}(s ; c)=\max _{t=1, \ldots, T} P_{t}^{d}(s ; c)$, which corresponds to the rounded parameter of the Poisson distribution. Thus we can restore the strategic default probabilities using the recovered parameter of the Poisson distribution:

$$
\sigma_{0, t}\left(s_{i, t} ; c_{i}\right)=\frac{P_{t}^{d}\left(s_{i, t}, c_{i}\right)-\hat{\lambda}(s ; c)^{t} e^{\hat{\lambda}(s ; c)} / t !}{1-\hat{\lambda}(s ; c)^{t} e^{\hat{\lambda}(s ; c)} / t !}
$$

Then we use the recovered strategic default probabilities to construct the second stage of our estimation.

The resulting estimates are reported in Table 10. The magnitudes of the coefficient estimates (except the discount factor) tend to be much larger in Table 10 (which nets out the impact of liquidity shocks through the Poisson assumption) compared with those in the baseline results of Table 8 (which does not). This is sensible because the financial incentives that make default less attractive, such as the costs of damaged credit, would be more relevant to the decision-making of borrowers who are not constrained by illiquidity than borrowers who struggle to meet monthly obligations (and thus see few options other than defaulting on the mortgage).

[Table 10 about here] 


\section{Simulations and Welfare Analysis}

In this section, we consider how borrowers' default behavior would change under various scenarios and compute the corresponding changes in borrower welfare. Our analysis uses the first-step policy function estimates to simulate borrowers' behavior under various "counterfactual" regimes. This approach is unconventional and deserves discussion. When we conduct counterfactual analysis using the first-step policy function estimates, one might worry about the Lucas critique. However, given the individual-level, panel structure of our data, our setup is not subject to this critique so long as two requirements are met. First, for each scenario, the forward-simulated distribution of state variables must remain in the empirical support of the policy functions. Note that in our panel data, we have much contemporaneous variation in home prices, monthly payments, credit quality, and so on. Our policy function is a valid description of optimal behavior for any realization of state variables in the empirical support. Therefore, we can use the first-step policy function estimates to determine how outcomes would change so long as the scenario under consideration does not lead to simulated values of state variables lying outside the empirical support. For example, we could predict the trajectory of borrowers' default behavior for a scenario in which all housing markets experience the same evolution of home prices as a particular MSA observed in the data. More generally, we can study any scenario that involves situations that actually occurred for some subset of borrowers in the data. A second requirement is that the transitions of the state variables (and expectations about them) must be unchanged under the counterfactuals, because the first-step policy function estimates are implicitly conditioned on the transition functions. We judiciously choose our simulation exercises that meet these requirements. ${ }^{29}$

Throughout our counterfactual exercises, we maintain a couple of key assumptions. First, we assume that the evolution of the macro state variables follows an exogenous process. This partial equilibrium approach makes the problem more tractable. A general equilibrium model wherein home prices and interest rates are endogenously determined is beyond the scope of this paper. In particular, such a general approach would require modeling how default decisions would feed into the determination of home prices, which is not an easy task.

Furthermore, our model addresses default decisions of borrowers conditional on their having already obtained a mortgage. As such, our model cannot be used to predict how loan originations would change under the various scenarios. All simulation exercises in this paper solely focus on the default behavior of existing loans that have been originated.

\footnotetext{
${ }^{29}$ As discussed in the Introduction, one of the advantages of this approach over the conventional approach of re-solving for the new equilibrium is a reduced computational burden. We find that it takes almost a week to run each counterfactual scenario even under our computationally lighter approach.
} 
In order to understand the total welfare impact of the proposed policies and market participants' willingness to participate in the proposed programs, we would need to additionally formulate lenders' value functions, specify the spillover effects of borrowers' default decisions on the macroeconomy, and specify the implementation costs of the proposed policies, among other things. These additional steps are beyond the scope of this paper, but we believe that understanding borrowers' behavior and borrower welfare changes under various policy levers is a useful first step.

\subsection{Counterfactual Scenarios}

Some of our counterfactual scenarios are intended to shed light on the relative importance of the major factors that contributed to higher default rates in recent years. Others are intended to assess the impact of various foreclosure mitigation policies. Because the actual policy interventions that have been implemented since the financial crisis have tended to be very multidimensional (and have applied to subsets of borrowers according to complex rules, implying that the eligible groups cannot easily be identified in our data), the general spirit of the exercise is to explore the effects of specific aspects of the programs as opposed to any particular policy implemented by the government.

The subprime mortgage crisis of 2007 was partly characterized by an unusually large fraction of subprime mortgages originated in 2006 becoming delinquent or going into foreclosure very soon after origination. For instance, the cumulative empirical probability of default by the end of 2007 is $10.81 \%$ for mortgages originated in 2006, compared with $6.48 \%$ for mortgages originated in 2004, even though the older loans have had more time over which to default. The first set of simulations focuses on explaining this difference in performance between loans of different vintages:

1. To quantify the importance of falling home prices in explaining the observed increase in defaults, we ask what the aggregate default rate among subprime borrowers would have been under alternative evolutionary paths for home prices. Specifically, we ask how all loans in the data that were alive as of January 2004 would have fared up through the censoring date (December 2009) if in that year homes in all markets had experienced the same precipitous decline in value as the average Las Vegas house three years later in 2007 (Scenario 1). By comparing the predicted default rates given actual home price changes with predicted default rates under the counterfactual scenario, we can determine how home price declines affect borrowers' default behavior. Another exercise simulates the default behavior of all subprime loans that were alive as of January 2006 under the counterfactual scenario in which all homes nationwide experience an increase in value in the year 2006 equalling that experienced by the average Las Vegas house two years earlier, in 2004 
(Scenario 2). This exercise tells us how the mortgage market would have performed in 2007-2009 if the housing bubble of the earlier years had continued.

2. In our earlier work (Bajari, Chu and Park (2011)), we found that deterioration over time in the credit quality of subprime borrowers was another major factor behind the recent increase in subprime defaults. To investigate this issue, we examine how much lower aggregate default rates would have been if the borrowers who took out loans in the later years had had the same overall credit quality as the borrowers from earlier years. Specifically, we shift the distribution of FICO scores for new borrowers in 2006 upward to match the mean FICO score among new borrowers in 2004. We then consider the set of loans originated in 2006 and simulate the borrowers' default behavior through the censoring date of December 2009 (Scenario 3).

The second set of simulations evaluates the effects of foreclosure mitigation policies:

1. How effective would mortgage principal writedowns be? Scenario 4 considers the effect of a $10 \%$ principal writedown on all outstanding loans; Scenario $\mathbf{5}$ considers a $20 \%$ writedown.

2. What effect would a cap on the loan-to-value ratio have? It is widely believed that loosened underwriting standards, such as the relaxation of downpayment requirements, paved the way for the mortgage crisis. Scenario 6 considers what would happen if LTVs at origination were capped at 0.8 (20\% downpayment) for all borrowers whose actual LTVs at origination exceeded 0.8; Scenario 7 caps the original LTV at 0.9 (10\% downpayment). Such a stricter requirement reduces the chance of borrowers going underwater even if home prices decline, thereby reducing the incentive to default.

In Table 11, we report simulation results for the counterfactual cases, which we show alongside the baseline model predictions for comparison. The results for Scenarios 1 and 2 indicate that housing price appreciation causes a meaningful reduction in default. Our model explains this effect in part by giving borrowers more net equity at each point in time, relative to the baseline case. As well, autocorrelation over time in housing prices implies that higher current appreciation leads to higher expectations for future appreciation, which reduces the incentive to default. The reverse is true when we subject borrowers to a large price decline: borrowers are much more likely to default because the price decline immediately pushes some borrowers deep into negative net equity, reducing the loss from walking away from the loan, and also because the realized price decline creates expectations of future price declines.

[Table 11 about here] 
Increasing the overall level of FICO scores of the borrower pool significantly reduces the aggregate default probability. This suggests that loosened underwriting standards, which permitted consumers with low credit quality to obtain mortgages, was a significant contributor to the higher default rates among subprime mortgages in recent years. Principal writedowns have the intended effect of reducing default and the effects are substantial. Principal writedowns reduce the propensity to default through two channels. First, a reduction in loan size increases borrowers' net equity in their homes. Second, principal writedowns reduce the monthly payments and make the loans more affordable. ${ }^{30}$ Finally, the effect of the LTV caps is qualitatively similar but smaller in magnitude than that of our principal writedown scenarios. This difference in magnitude is primarily driven by the fact that our LTV caps are binding only for a small fraction of borrowers, whereas the principal writedowns we consider are applied to the entire population.

\subsection{Borrower Welfare}

To understand the consequences of the above scenarios for borrower welfare, we compute borrower welfare in two ways. First, we compute the ex ante value function of each borrower in each time period under both the baseline and counterfactual scenarios using (1). As a summary measure of how borrowers' welfare changes between the two scenarios, we compare the mean of the ex ante values across borrowers and over time between the two scenarios. ${ }^{31}$ Second, we compute compensating variation, which is the amount of additional money the borrower must receive in order to bring his utility under the counterfactual scenario back to his initial utility level.

In Table 12, we report how mortgage borrowers' welfare changes under the various scenarios using the first approach. With exception of Scenario 3, our model predicts that borrowers' welfare should increase in scenarios in which the aggregate default rate goes down, and decrease when the aggregate default rate goes up. ${ }^{32}$ The only scenario in which the relationship is theoretically ambiguous is Scenario 3. When borrowers' credit quality goes up, there are two opposing effects. On the one hand, borrowers are less likely to default, which leads to greater welfare. On the other hand, higher FICO scores imply greater utility loss in the case of default, because the costs of default are higher for borrowers with better credit. This could lead to lower welfare given the same rate of default. The welfare figure in Table 12 shows that

\footnotetext{
${ }^{30}$ Our finding that principal writedowns would be very effective in reducing defaults may explain why Hope for Homeowners was the first program introduced by the government in response to the mortgage crisis. The problem the program faced was that lenders were very reluctant to participate and write down mortgage principal.

${ }^{31}$ Due to nonstationarity of the value function, the average of the ex ante values over time does not have a clear meaning. However, we think the average is still a useful summary measure for comparison of welfare between two scenarios since the degree of nonstationarity is the same between the two scenarios.

${ }^{32}$ The absolute level of the welfare figures in Table 12 does not mean anything as the ex ante values are unitless. What matters is the difference in the welfare figures between the baseline scenario and the counterfactual scenario.
} 
the former effect dominates, with borrowers' overall welfare increasing when their credit quality goes up.

[Table 12 about here]

Although Table 12 indicates the direction and relative magnitudes of borrower welfare changes under each scenario, we cannot assign any meaningful scale to the numbers because ex ante values are unitless (Indeed, as shown, some of the welfare levels are negative). Compensating variation, on the other hand, can be expressed in dollars.

We define the "one-time compensating variation" (OTCV) as the lump-sum compensation (either a reduction or increase in payment) needed to bring the borrower's utility under the considered counterfactual scenario to the original utility level. By assumption, the OTCV does not affect the transition path of income - in other words, a mechanism for implementing the OTCV would be to present consumers with a lump-sum while informing them that the compensation is for one time only. The OTCV is thus a variant of the standard compensating variation used in microeconomics, and can be applied to a dynamic model with randomness in borrowers' utility functions. If $u_{k}(\cdot)$ is the per-period utility of consumer from choosing option $k$, the OTCV in the case of extreme-value distributed unobserved shocks is implied by the following equality:

$$
V_{i, t}\left(w_{i, t}, y_{i, t}\right)=\log \left(\sum_{k=0}^{2} \exp \left(u_{k}\left(w_{i, t}^{\prime}, y_{i, t}^{\prime}-O T C V_{i, t}\right)+\beta E\left[V_{i, t+1}\left(w_{i, t+1}, y_{i, t+1}\right) \mid w_{i, t}^{\prime}, y_{i, t}^{\prime}, k\right]\right)\right)
$$

where $V_{i, t}(\cdot, \cdot)$ is the ex ante value function, $y_{i, t}$ is the income of the borrower, and $w_{i, t}$ is the vector of all other state variables. Values $\left(w_{i, t}, y_{i, t}\right)$ correspond to the values before the change and values $\left(w_{i, t}^{\prime}, y_{i, t}^{\prime}\right)$ correspond to the values after the counterfactual change. Table 13 reports the average onetime compensating variation across borrowers in the sample for each scenario. ${ }^{33}$

[Table 13 about here]

As expected, we see that scenarios that would lead to a large reduction in the probability of default have large OTCV. For instance, our results show that a uniform $10 \%$ reduction in outstanding mortgage balance for the pool of borrowers in our sample would reduce the overall default probability by $22 \%$, and that each borrower would be willing to pay up to $\$ 16,643$ on average to enjoy the principal writedown

\footnotetext{
${ }^{33}$ In computing the OTCV, we determine the utility of money using the estimated coefficient on monthly payments instead of the estimated coefficient on income for two reasons. First, some of the stated incomes may be misrepresented in the data. Especially in the case of low-doc loans, income falsification is a big concern (see Jiang, Nelson and Vytlacil (2011)). Second, the coefficient on income may reflect not just the effect of income in the utility of each action, but also additional, confounding effects such as the impact of income on the ability to refinance. The monthly payment variable is less likely to suffer from such problems.
} 
instead of going back to the original circumstance. Under a uniform $20 \%$ reduction in outstanding mortgage balance, the overall default probability would go down by $38 \%$, and each borrower would be willing to pay up to $\$ 29,511$ on average to enjoy the principal writedown instead of going back to the original circumstance. ${ }^{34}$

\section{Conclusion}

We have estimated and simulated a dynamic structural model of mortgage default. Using our model, we have quantified the importance of home price declines as well as looser underwriting standards in creating the conditions that led to the recent wave of mortgage defaults. We have also used the model to investigate the impact of various aspects of interventions that have been proposed by regulators in response to the mortgage crisis.

In addition to answering these timely economic questions, our paper makes a few methodological contributions. First, we propose an estimation method for dynamic discrete choice problems with finite horizon that is intuitive and easy to implement. Second, we prove that we can identify the discount factor by exploiting the features of the empirical setup.

\footnotetext{
${ }^{34}$ When we make an alternative normalization setting default utility to zero, our welfare results do not change qualitatively.
} 


\section{References}

[1] Abbring, Jaap. 2012. "Mixed Hitting-Time Models." Econometrica, 80(2): 783-819.

[2] Ai, Chunrong and Xiaohong Chen. 2003. "Efficient Estimation of Models with Conditional Moment Restrictions Containing Unknown Functions." Econometrica, 71(6): 1795-1843.

[3] Ahn, Hyungtaik, and Charles Manski. 1993. "Distribution Theory for the Analysis of Binary Choice under Uncertainty with Nonparametric Estimation of Expectations." Journal of Econometrics, 56(3): 291-321.

[4] Andrews, Donald. 1991. "Asymptotic Normality of Series Estimators for Nonparametric and Semiparametric Regression Models." Econometrica, 59(2): 307-345.

[5] Arcidiacono, Peter and Robert Miller. 2011. "Conditional Choice Probability Estimation of Dynamic Discrete Choice Models with Unobserved Heterogeneity." Econometrica, 7(6): 1823-1868.

[6] Aron-Dine, Aviva, Liran Einav, Amy Finkelstein, and Mark Cullen. 2012. "Moral Hazard in Health Insurance: How Important Is Forward Looking Behavior?" Working Paper.

[7] Bajari, Patrick, Sean Chu, and Minjung Park. 2011. "An Empirical Model of Subprime Mortgage Default from 2000 to 2007." Working Paper.

[8] Bajari, Patrick, Han Hong and Denis Nekipelov. 2012. "Game Theory and Econometrics: A Survey of Some Recent Research." forthcoming in Advances in Econometrics: Tenth World Congress of Econometric Society.

[9] Chen, Xiaohong. 2007. "Large Sample Sieve Estimation of Semi-nonparametric Models." Handbook of Econometrics, 7: 5549-5632.

[10] Chen, Xiaohong, Oliver Linton and Ingrid van Keilegom. 2003. "Estimation of Semiparametric Models when the Criterion Function Is Not Smooth." Econometrica, 71(5): 1591-1608.

[11] Chen, Xiaohong, Victor Chernozhukov, Sokbae Lee and Whitney Newey. 2011. "Local Identification of Nonparametric and Semiparametric Models." Working Paper.

[12] Chung, Doug, Thomas Steenburgh and K. Sudhir. 2011. "Do Bonuses Enhance Sales Productivity? A Dynamic Structural Analysis of Bonus-Based Compensation Plans." Working Paper.

[13] Demyanyk, Yuliya, and Otto van Hemert. 2011. "Understanding the Subprime Mortgage Crisis." Review of Financial Studies, 24(6): 1848-1880. 
[14] Deng, Yongheng, John M. Quigley, and Robert van Order. 2000. "Mortgage Terminations, Heterogeneity, and the Exercise of Mortgage Options." Econometrica, 68(2): 275-307.

[15] Einav, Liran, Amy Finkelstein, Stephen Ryan, Paul Schrimpf, and Mark R. Cullen. 2013. "Selection on Moral Hazard in Health Insurance." American Economic Review, 103(1): 1-44.

[16] Einav, Liran, Mark Jenkins, and Jonathan Levin. 2012. "Contract Pricing in Consumer Credit Markets." Econometrica, 80(4): 1387-1432.

[17] Fang, Hanming, and Yang Wang. 2012. "Estimating Dynamic Discrete Choice Models with Hyperbolic Discounting, with an Application to Mammography Decisions." Working Paper.

[18] Foster, Chester and Robert Van Order. 1984. "An Option-Based Model of Mortgage Default." Housing Finance Review, 3: 351-372.

[19] Foote, Christopher, Kristopher Gerardi, and Paul Willen. 2008. "Negative Equity and Foreclosure: Theory and Evidence." Journal of Urban Economics, 64(2): 234-245.

[20] Frederick, Shane, George Loewenstein and Ted O'Donohue. 2002. "Time Discounting and Time Preference: A Critical Review." Journal of Economic Literature, 40: 350-401.

[21] Gerardi, Kristopher, Andreas Lehnert, Shane Sherlund, and Paul Willen. 2008. "Making Sense of the Subprime Crisis." Brookings Papers on Economic Activity, 2008: 69-145.

[22] Gautam Gowrisankaran and Marc Rysman. 2012. "Dynamics of Consumer Demand for New Durable Goods." Working Paper.

[23] Hausman, Jerry. 1979. "Individual Discount Rates and the Purchase and Utilization of EnergyUsing Durables." Bell Journal of Economics, 10(1): 33-54.

[24] Heckman, James and Burton Singer. 1984. "A Method for Minimizing the Impact of Distributional Assumptions in Econometric Models for Duration Data." Econometrica, 52(2): 271-320.

[25] Hotz, Joseph, and Robert Miller. 1993. "Conditional Choice Probabilities and the Estimation of Dynamic Models." Review of Economic Studies, 60(3): 497-529.

[26] Hu, Yingyao and Matthew Shum. 2012. "Nonparametric Identification of Dynamic Models with Unobserved State Variables." Journal of Econometrics, 171(1): 32-44.

[27] Jiang, Wei, Ashlyn Nelson and Edward Vytlacil. 2011. "Liar's Loan? Effects of Origination Channel and Information Falsification on Mortgage Loan Delinquency." Working Paper. 
[28] Kasahara, Hiroyuki and Katsumi Shimotsu. 2009. "Nonparametric Identification of Finite Mixture Models of Dynamic Discrete Choices." Econometrica, 77(1): 135-175.

[29] Keys, Benjamin, Tanmoy Mukherjee, Amit Seru, and Vikrant Vig. 2010. "Did Securitization Lead to Lax Screening? Evidence From Subprime Loans." Quarterly Journal of Economics, 125(1): 307-362.

[30] Khan, Shakeeb and Denis Nekipelov, 2011. "Information Structure and Statistical Information in Discrete Response Models." ERID Working paper.

[31] Khan, Shakeeb and Denis Nekipelov, 2012. "On Uniform Inference in Nonlinear Models with Endogeneity." ERID Working paper.

[32] Magnac, Thierry, and David Thesmar. 2002. "Identifying Dynamic Discrete Decision Processes." Econometrica, 70(2): 801-816.

[33] Mammen, Enno, Christoph Rothe, and Melanie Schienle. 2012. "Nonparametric Regression With Nonparametrically Generated Covariates." Annals of Statistics, 40(2): 1132-1170.

[34] Manski, Charles. 1991. "Nonparametric Estimation of Expectations in the Analysis of Discrete Choice under Uncertainty." Nonparametric and Semiparametric Methods in Econometrics and Statistics: Proceedings of the Fifth International Symposium in Economic Theory and Econometrics, Cambridge University Press.

[35] Manski, Charles. 1993. "Identification of Endogenous Social Effects: The Reflection Problem." Review of Economic Studies, 60(3): 531-542.

[36] Manski, Charles. 2000. "Identification Problems and Decisions under Ambiguity: Empirical Analysis of Treatment Response and Normative Analysis of Treatment Choice." Journal of Econometrics, 95(2): 415-442.

[37] Newey, Whitney. 1997. "Convergence Rates and Asymptotic Normality for Series Estimators." Journal of Econometrics, 79: 147-168.

[38] Newey, Whitney and James Powell. 2003. "Instrumental Variable Estimation of Nonparametric Models." Econometrica, 71(5): 1565-1578.

[39] Pollard, David. 1984. Convergence of Stochastic Processes, Springer-Verlag.

[40] Rust, John. 1987. "Optimal Replacement of GMC Bus Engines: An Empirical Model of Harold Zurcher." Econometrica, 55(5): 999-1033. 
[41] Tracy, Joseph and Joshua Wright. 2012. "Payment Changes and Default Risk: The Impact of Refinancing on Expected Credit Losses." Working Paper.

[42] van der Vaart, Aad and Jon Wellner. 1996. Weak Convergence and Empirical Processes, Springer.

[43] von Furstenberg, George. 1969. "Default Risk on FHA-Insured Home Mortgages as a Function of the Term of Financing: A Quantitative Analysis." Journal of Finance, 24(3): 459-477.

[44] Wong, Wing Hung and Xiaotong Shen. 1995. "Probability Inequalities for Likelihood Ratios and Convergence Rates of Sieve MLES." Annals of Statistics, 23(2): 339-362.

[45] Yao, Song, Carl F. Mela, Jeongwen Chiang, and Yuxin Chen. 2012. "Determining Consumers' Discount Rates With Field Studies." Journal of Marketing Research, forthcoming 
Table 1: Definition of Variables

\begin{tabular}{|c|l|}
\hline Variable & \multicolumn{1}{|c|}{ Definition } \\
\hline $\begin{array}{c}\text { Owner-Occupier } \\
\text { Purchase Loan }\end{array}$ & $=1$ if the loan is made with the intent to occupy the house, =0 if for investment. \\
Low Doc & $=1$ if purpose of the loan is house purchase, 0 if refinance loan without cash-out. \\
Multiple Liens & $=1$ if the borrower has other, junior mortgages, =0 otherwise. \\
FICO & FICO score, a credit score developed by Fair Issac \& Co. \\
& Scores range between 300 and 850. Higher scores indicate higher credit quality. \\
Income & Monthly income. \\
Contractual Interest Rate & Interest rate specified by the mortgage. \\
Market Rate & Current market interest rate. We impute borrower-specific market rate. \\
Housing Value & Current housing value. \\
Net Equity & Current housing value - Outstanding loan balance. \\
Payment & Monthly payment due. \\
Prepayment Penalty & $=1$ if the loan has prepayment penalty, = 0 otherwise. \\
Unemployment Rate & Monthly unemployment rate at the county level. \\
\hline
\end{tabular}


Table 2: Summary Statistics for Estimation Sample

\begin{tabular}{|c|c|c|c|c|c|}
\hline & Defaulted & Prepaid & Censored & \multicolumn{2}{|c|}{ All loans } \\
\hline \multicolumn{6}{|c|}{ Time-invariant loan-level variables } \\
\hline & Mean & Mean & Mean & Mean & Std. Dev \\
\hline \% Owner-Occupier Loans & 87.5 & 75.8 & 63.5 & 73.9 & 43.9 \\
\hline$\%$ Purchase Loans & 59.9 & 60.0 & 55.3 & 58.6 & 49.2 \\
\hline FICO Score & 626.4 & 674.6 & 691.7 & 672.6 & 74.4 \\
\hline Monthly Payment & 1287.3 & 1406.1 & 1236.5 & 1339.9 & 1163.6 \\
\hline \% Low Documentation Loans & 36.4 & 41.7 & 38.8 & 40.1 & 49 \\
\hline Contractual Interest Rate & 8.528 & 7.854 & 6.722 & 7.624 & 1.75 \\
\hline Appraisal Value of House $(\$ \mathrm{~m})$ & 0.214 & 0.272 & 0.274 & 0.264 & 0.218 \\
\hline Monthly Income & 5239.4 & 6342.9 & 6340.8 & 6182.7 & 6497.8 \\
\hline \% Loans with Multiple Liens & 23.8 & 9.9 & 19.1 & 14.6 & 35.3 \\
\hline \multicolumn{6}{|c|}{ Time-dependent loan-level variables, as last observed for each loan } \\
\hline & Mean & Mean & Mean & Mean & Std. Dev \\
\hline Loan Age in Months & 31.44 & 24.41 & 63.38 & 36.7 & 23.7 \\
\hline \% Loans with Prepayment Penalty & 43.8 & 30 & 2.5 & 24.0 & 42.7 \\
\hline Net Equity $(\$ \mathrm{~m})$ & 0.038 & 0.133 & 0.079 & 0.103 & 0.146 \\
\hline Current Housing Value $(\$ \mathrm{~m})$ & 0.207 & 0.327 & 0.255 & 0.289 & 0.245 \\
\hline Monthly HPI Growth Rate (\%) & -0.2 & 0.8 & -0.4 & 0.3 & 1.7 \\
\hline Market Interest Rate & 8.26 & 7.202 & 6.221 & 7.066 & 1.89 \\
\hline Unemployment Rate & 6.666 & 5.348 & 9.668 & 6.787 & 2.714 \\
\hline Number of Loans & 1729 & 6770 & 3456 & & 1955 \\
\hline
\end{tabular}


Table 3: Summary Statistics by Origination Year

\begin{tabular}{|l|cccccccc|}
\hline & 2000 & 2001 & 2002 & 2003 & 2004 & 2005 & 2006 & 2007 \\
\hline \% Loans that Default by 12/2009 & 15.7 & 11.35 & 10.6 & 6.86 & 8.47 & 22.83 & 36.01 & 31.88 \\
\% Loans that Prepay by 12/2009 & 81.83 & 85.10 & 78.5 & 58.88 & 48.23 & 30.42 & 15.5 & 11.88 \\
Avg Duration to Default in Months & 27.69 & 32.19 & 33.64 & 40 & 39.3 & 33.52 & 25.8 & 21.18 \\
Avg Duration to Prepayment in Months & 25.61 & 24.79 & 23.88 & 26.35 & 23.05 & 20.52 & 19.57 & 17.64 \\
\% Owner-Occupier Loans & 85.74 & 94.4 & 78.04 & 50.2 & 62.73 & 84.08 & 91.02 & 87.83 \\
\% Purchase Loans & 78.2 & 53.7 & 49.3 & 51.2 & 67.8 & 52.2 & 64.1 & 57.4 \\
FICO Score & 640.7 & 656.2 & 669.6 & 697.4 & 702.1 & 655.7 & 648.4 & 656 \\
Monthly Payment & 1262.6 & 1727 & 1320.1 & 1190 & 1328.1 & 1206.6 & 1551.8 & 1556.8 \\
\% Low Documentation Loans & 34.3 & 38.9 & 35 & 42.9 & 41.1 & 43.9 & 39.1 & 52.2 \\
Contractual Interest Rate & 10.193 & 8.971 & 7.768 & 6.625 & 6.554 & 6.984 & 7.778 & 7.816 \\
Appraisal Value of House (\$m) & 0.184 & 0.309 & 0.251 & 0.273 & 0.292 & 0.246 & 0.284 & 0.293 \\
Monthly Income & 5209.6 & 7099 & 6049.6 & 5682.5 & 7262.3 & 5360.6 & 6554.2 & 7667 \\
\% Loans with Multiple Liens & 0.6 & 0.6 & 2 & 10.7 & 24.3 & 27.4 & 42 & 19.7 \\
\% Loans with Prepayment Penalty & 33.8 & 35.5 & 28.9 & 15.7 & 13.1 & 24.8 & 25 & 42 \\
Net Equity (\$m)* & 0.073 & 0.141 & 0.124 & 0.153 & 0.118 & 0.046 & 0.021 & 0.016 \\
Monthly HPI Growth Rate (\%)* & 0.632 & 0.775 & 0.811 & 0.43 & 0.229 & -0.4 & -0.765 & -0.699 \\
Number of Loans & 1431 & 1215 & 1726 & 2697 & 2007 & 1476 & 1058 & 345 \\
\hline
\end{tabular}

*: as last observed for each loan

Table 4: Duration to Default or Prepayment

\begin{tabular}{|ccccccccc|}
\hline \multicolumn{8}{|c|}{ Duration to Default (in months) } \\
$1-6$ & $7-12$ & $13-18$ & $19-24$ & $25-30$ & $31-36$ & $37-42$ & $43-48$ & $>48$ months \\
$2.89 \%$ & $14.11 \%$ & $12.96 \%$ & $11.91 \%$ & $10.87 \%$ & $12.32 \%$ & $8.79 \%$ & $6.82 \%$ & $19.32 \%$ \\
\hline \multicolumn{7}{c|}{ Duration to Prepayment (in months) } \\
$1-6$ & $7-12$ & $13-18$ & $19-24$ & $25-30$ & $31-36$ & $37-42$ & $43-48$ & $>48$ months \\
$1.91 \%$ & $18.29 \%$ & $23.15 \%$ & $17.09 \%$ & $12.02 \%$ & $8.60 \%$ & $6.31 \%$ & $3.41 \%$ & $9.23 \%$ \\
\hline
\end{tabular}


Table 5: In-Sample Fit of First-Step Estimates

\begin{tabular}{|c|cc|cc|cc|}
\hline & \multicolumn{2}{|c|}{ Default Probability } & \multicolumn{2}{|c|}{ Prepay Probability } & \multicolumn{2}{|c|}{ Pay Probability } \\
\cline { 2 - 8 } & Prediction & Data & Prediction & Data & Prediction & Data \\
\hline All & 0.0046 & 0.0047 & 0.0178 & 0.0179 & 0.9775 & 0.9774 \\
\hline FICO G1 & 0.0107 & 0.0109 & 0.0209 & 0.0209 & 0.9684 & 0.9682 \\
FICO G2 & 0.0085 & 0.0083 & 0.0168 & 0.0171 & 0.9747 & 0.9746 \\
FICO G3 & 0.0059 & 0.0060 & 0.0187 & 0.0188 & 0.9754 & 0.9753 \\
FICO G4 & 0.0025 & 0.0026 & 0.0194 & 0.0190 & 0.9780 & 0.9784 \\
FICO G5 & 0.0011 & 0.0010 & 0.0167 & 0.0166 & 0.9822 & 0.9824 \\
FICO G6 & 0.0006 & 0.0010 & 0.0123 & 0.0138 & 0.9872 & 0.9852 \\
\hline Payment G1 & 0.0032 & 0.0030 & 0.0130 & 0.0136 & 0.9838 & 0.9834 \\
Payment G2 & 0.0041 & 0.0044 & 0.0132 & 0.0127 & 0.9826 & 0.9829 \\
Payment G3 & 0.0049 & 0.0047 & 0.0152 & 0.0154 & 0.9798 & 0.9799 \\
Payment G4 & 0.0051 & 0.0054 & 0.0194 & 0.0190 & 0.9755 & 0.9756 \\
Payment G5 & 0.0048 & 0.0048 & 0.0230 & 0.0235 & 0.9722 & 0.9717 \\
Payment G6 & 0.0050 & 0.0047 & 0.0247 & 0.0252 & 0.9704 & 0.9700 \\
\hline Low Doc = 0 & 0.0048 & 0.0048 & 0.0168 & 0.0169 & 0.9784 & 0.9782 \\
Low Doc =1 & 0.0045 & 0.0044 & 0.0196 & 0.0195 & 0.9759 & 0.9760 \\
\hline Multi Liens = 0 & 0.0041 & 0.0042 & 0.0188 & 0.0188 & 0.9771 & 0.9770 \\
Multi Liens =1 & 0.0079 & 0.0078 & 0.0118 & 0.0124 & 0.9804 & 0.9798 \\
\hline Net Equity G1 & 0.0147 & 0.0147 & 0.0045 & 0.0041 & 0.9808 & 0.9812 \\
Net Equity G2 & 0.0067 & 0.0066 & 0.0117 & 0.0120 & 0.9816 & 0.9814 \\
Net Equity G3 & 0.0047 & 0.0048 & 0.0181 & 0.0179 & 0.9772 & 0.9774 \\
Net Equity G4 & 0.0027 & 0.0030 & 0.0234 & 0.0234 & 0.9738 & 0.9736 \\
Net Equity G5 & 0.0015 & 0.0014 & 0.0233 & 0.0244 & 0.9753 & 0.9742 \\
Net Equity G6 & 0.0007 & 0.0006 & 0.0181 & 0.0174 & 0.9812 & 0.9820 \\
\hline & \multicolumn{2}{|c|}{ Likelihood Ratio Index: 0.1525} & & \\
\hline
\end{tabular}

This table examines probability of default/prepay/pay in each period. G1: bottom $10 \%$ in the specified variable; G2: 10\%-25\%; G3: 25\%-50\%; G4: 50\%-75\%; G5: 75\%-90\%; G6: top $10 \%$ 
Table 6: Out-of-Sample Fit of First-Step Estimates

\begin{tabular}{|c|cc|cc|cc|}
\hline & \multicolumn{2}{|c|}{ Default Probability } & \multicolumn{2}{c|}{ Prepay Probability } & \multicolumn{2}{c|}{ Pay Probability } \\
\cline { 2 - 7 } & Prediction & Data & Prediction & Data & Prediction & Data \\
\hline All & 0.0046 & 0.0048 & 0.0179 & 0.0178 & 0.9775 & 0.9774 \\
\hline FICO G1 & 0.0106 & 0.0111 & 0.0210 & 0.0206 & 0.9684 & 0.9683 \\
FICO G2 & 0.0080 & 0.0091 & 0.0170 & 0.0162 & 0.9750 & 0.9747 \\
FICO G3 & 0.0060 & 0.0058 & 0.0186 & 0.0194 & 0.9753 & 0.9748 \\
FICO G4 & 0.0025 & 0.0027 & 0.0197 & 0.0185 & 0.9779 & 0.9788 \\
FICO G5 & 0.0011 & 0.0010 & 0.0164 & 0.0167 & 0.9825 & 0.9823 \\
FICO G6 & 0.0007 & 0.0010 & 0.0124 & 0.0137 & 0.9869 & 0.9853 \\
\hline Payment G1 & 0.0035 & 0.0028 & 0.0138 & 0.0135 & 0.9827 & 0.9838 \\
Payment G2 & 0.0040 & 0.0047 & 0.0137 & 0.0119 & 0.9822 & 0.9834 \\
Payment G3 & 0.0047 & 0.0049 & 0.0153 & 0.0149 & 0.9800 & 0.9802 \\
Payment G4 & 0.0051 & 0.0054 & 0.0190 & 0.0195 & 0.9759 & 0.9752 \\
Payment G5 & 0.0048 & 0.0048 & 0.0225 & 0.0236 & 0.9727 & 0.9716 \\
Payment G6 & 0.0049 & 0.0053 & 0.0251 & 0.0257 & 0.9700 & 0.9690 \\
\hline Low Doc = 0 & 0.0047 & 0.0049 & 0.0167 & 0.0169 & 0.9785 & 0.9782 \\
Low Doc = 1 & 0.0044 & 0.0046 & 0.0198 & 0.0193 & 0.9757 & 0.9761 \\
\hline Multi Liens = 0 & 0.0041 & 0.0043 & 0.0189 & 0.0187 & 0.9770 & 0.9771 \\
Multi Liens = 1 & 0.0077 & 0.0081 & 0.0114 & 0.0126 & 0.9809 & 0.9793 \\
\hline Net Equity G1 & 0.0144 & 0.0144 & 0.0043 & 0.0041 & 0.9813 & 0.9815 \\
Net Equity G2 & 0.0068 & 0.0069 & 0.0119 & 0.0117 & 0.9813 & 0.9814 \\
Net Equity G3 & 0.0049 & 0.0046 & 0.0183 & 0.0178 & 0.9768 & 0.9776 \\
Net Equity G4 & 0.0025 & 0.0035 & 0.0233 & 0.0233 & 0.9742 & 0.9732 \\
Net Equity G5 & 0.0012 & 0.0017 & 0.0230 & 0.0243 & 0.9759 & 0.9741 \\
Net Equity G6 & 0.0008 & 0.0005 & 0.0188 & 0.0174 & 0.9803 & 0.9822 \\
\hline
\end{tabular}

This table examines probability of default/prepay/pay in each period. Also see the notes in Table 5. 
Table 7: Simulated Probability of Eventual Default or Prepay by End of 2009

\begin{tabular}{|c|c|c|c|c|c|}
\hline & & Prob. Default & Duration to Default & Prob. Prepay & Duration to Prepay \\
\hline \multirow[t]{2}{*}{ All } & Prediction & 0.1482 & 34.1782 & 0.5536 & 27.5309 \\
\hline & Data & 0.1446 & 31.834 & 0.5663 & 24.9022 \\
\hline \multirow[t]{2}{*}{ FICO G1 } & Prediction & 0.2968 & 28.5291 & 0.5423 & 29.9263 \\
\hline & Data & 0.2828 & 27.7744 & 0.5584 & 26.3597 \\
\hline \multirow[t]{2}{*}{ FICO G2 } & Prediction & 0.2399 & 30.8991 & 0.4972 & 28.2917 \\
\hline & Data & 0.2438 & 30.2051 & 0.5026 & 25.401 \\
\hline \multirow[t]{2}{*}{ FICO G3 } & Prediction & 0.1778 & 33.514 & 0.5391 & 27.2472 \\
\hline & Data & 0.1743 & 33.3803 & 0.5603 & 24.8361 \\
\hline \multirow[t]{2}{*}{ FICO G4 } & Prediction & 0.085 & 37.2138 & 0.6103 & 26.1825 \\
\hline & Data & 0.0803 & 36.7915 & 0.6178 & 23.9398 \\
\hline \multirow[t]{2}{*}{ FICO G5 } & Prediction & 0.0463 & 40.5877 & 0.6022 & 26.8731 \\
\hline & Data & 0.0353 & 39.2546 & 0.588 & 24.4339 \\
\hline \multirow[t]{2}{*}{ FICO G6 } & Prediction & 0.0284 & 41.8558 & 0.4859 & 28.6893 \\
\hline & Data & 0.0389 & 30.381 & 0.5357 & 26.0796 \\
\hline \multirow[t]{2}{*}{ Net Equity G1 } & Prediction & 0.2869 & 32.3095 & 0.4235 & 29.783 \\
\hline & Data & 0.2861 & 28.5546 & 0.4315 & 28.9833 \\
\hline \multirow{2}{*}{ Net Equity G2 } & Prediction & 0.2148 & 33.7037 & 0.5125 & 30.2516 \\
\hline & Data & 0.2057 & 31.9563 & 0.5451 & 27.5251 \\
\hline \multirow[t]{2}{*}{ Net Equity G3 } & Prediction & 0.1511 & 34.3932 & 0.5502 & 27.1267 \\
\hline & Data & 0.1466 & 32.2371 & 0.5618 & 24.3602 \\
\hline \multirow[t]{2}{*}{ Net Equity G4 } & Prediction & 0.1034 & 34.2837 & 0.599 & 25.6506 \\
\hline & Data & 0.1082 & 32.6803 & 0.614 & 22.5144 \\
\hline \multirow[t]{2}{*}{ Net Equity G5 } & Prediction & 0.0635 & 35.3587 & 0.6209 & 25.4969 \\
\hline & Data & 0.0562 & 34.1 & 0.6169 & 24.9935 \\
\hline \multirow[t]{2}{*}{ Net Equity G6 } & Prediction & 0.0275 & 40.3674 & 0.5767 & 28.2123 \\
\hline & Data & 0.0164 & 39.1111 & 0.5327 & 25.2457 \\
\hline
\end{tabular}

This table examines probability of eventual default/prepay by the end of 2009. Duration is measured in months. Also see the notes in Table 5. 
Table 8: Structural Estimates of Per-Period Utility

\begin{tabular}{|c|c|c|c|}
\hline & Default & Prepay & Pay \\
\hline FICO & $-0.615(0.0819) * * *$ & & \\
\hline MSA dummies & Included & & \\
\hline Housing Value & & $0.0216(0.0335)$ & $0.0629(0.0182) * * *$ \\
\hline Monthly Payment & & $-0.0205(0.0049) * * *$ & $-0.0205(0.0049) * * *$ \\
\hline Prepayment Penalty & & $0.1343(0.0097) * * *$ & \\
\hline Income & & $-0.0034(0.0010) * * *$ & $0.0022(0.0002)$ *** \\
\hline Unemployment Rate & & $-0.2304(0.0051) * * *$ & $-0.0110(0.0030) * * *$ \\
\hline Low Doc & & $0.0185(0.0101) *$ & $-0.0210(0.0022) * * *$ \\
\hline Multiple Liens & & $0.0592(0.0157) * * *$ & $-0.0060(0.0042)$ \\
\hline$\beta\left(\right.$ coeff on $\left.\hat{E}\left[V_{t+1}\left(s_{i, t+1}\right) \mid s_{i, t}, a_{i, t}\right]\right)$ & & $0.9815(0.0033) * * *$ & $0.9815(0.0033) * * *$ \\
\hline No. of Obs & & 400493 & 400493 \\
\hline $\mathrm{R}^{2}$ & & 0.8675 & 0.9935 \\
\hline
\end{tabular}

SUR with constraints that coefficients on monthly payment and $\hat{E}\left[V_{t+1}\left(s_{i, t+1}\right) \mid s_{i, t}, a_{i, t}\right]$ are the same between the payment and prepayment equations. Bootstrapped standard errors are reported to account for estimation errors in first-step policy functions and ex ante value functions. 
Table 9: Estimates of Per-Period Utility for Various Subsamples

\begin{tabular}{|c|c|c|c|c|c|c|}
\hline & \multicolumn{3}{|c|}{ Loans for Home Purchase } & \multicolumn{3}{|c|}{ Loans for Refinancing } \\
\hline & Default & Prepay & Pay & Default & Prepay & Pay \\
\hline FICO & $-0.94(0.11)^{* * *}$ & & & $-1.04(0.13)^{* * *}$ & & \\
\hline MSA & Included & & & Included & & \\
\hline Housing Value & & $0.10(0.05)^{* *}$ & $0.09(0.02)^{* * *}$ & & $0.11(0.08)$ & $0.07(0.06)$ \\
\hline Payment & & $-0.04(0.005)^{* * *}$ & $-0.04(0.005)^{* * *}$ & & $0.02(0.02)$ & $0.02(0.015)$ \\
\hline $\mathrm{P} \_$Penalty & & $0.005(0.02)$ & & & $0.32(0.02)^{* * *}$ & \\
\hline Income & & $-0.004(0.001)^{* * *}$ & $0.003(0.0003)^{* * *}$ & & $-0.01(0.002)^{* * *}$ & $0.001(0.001)$ \\
\hline Unem. Rate & & $-0.23(0.01)^{* * *}$ & $-0.003(0.001)^{* * *}$ & & $-0.26(0.01)^{* * *}$ & $-0.02(0.008) * * *$ \\
\hline Low Doc & & $0.05(0.02)^{* * *}$ & $-0.02(0.002)^{* * *}$ & & $-0.11(0.02)^{* * *}$ & $-0.01(0.005)^{* *}$ \\
\hline Multi-Liens & & $0.15(0.02)^{* * *}$ & $-0.001(0.003)$ & & $-0.18(0.04)^{* * *}$ & $-0.003(0.01)$ \\
\hline$\beta$ & & $0.99(0.003) * * *$ & $0.99(0.003)^{* * *}$ & & $0.97(0.008) * * *$ & $0.97(0.008) * * *$ \\
\hline No. of Obs & & 221612 & 221612 & & 178881 & 178881 \\
\hline $\mathrm{R}^{2}$ & & 0.839 & 0.994 & & 0.942 & 0.995 \\
\hline & \multicolumn{3}{|c|}{ Owner-Occupiers } & \multicolumn{3}{|c|}{ Investors } \\
\hline & Default & Prepay & Pay & Default & Prepay & Pay \\
\hline FICO & $-0.84(0.15)^{* * *}$ & & & $0.05(0.5)$ & & \\
\hline MSA & Included & & & Included & & \\
\hline Housing Value & & $0.33(0.04)^{* * *}$ & $0.13(0.02)^{* * *}$ & & $-0.28(0.26)$ & $0.96(0.24)^{* * *}$ \\
\hline Payment & & $-0.05(0.005)^{* * *}$ & $-0.05(0.005)^{* * *}$ & & $-0.19(0.05)^{* * *}$ & $-0.19(0.05)^{* * *}$ \\
\hline $\mathrm{P} \_$Penalty & & $0.006(0.01)$ & & & $0.21(0.04)^{* * *}$ & \\
\hline Income & & $-0.01(0.002)^{* * *}$ & $0.004(0.001)^{* * *}$ & & $-0.01(0.002)^{* *}$ & $0.000(0.0004)$ \\
\hline Unem. Rate & & $-0.25(0.01)^{* * *}$ & $-0.009(0.004)^{* *}$ & & $-0.19(0.01)^{* * *}$ & $0.001(0.001)$ \\
\hline Low Doc & & $-0.02(0.01)$ & $-0.03(0.003)^{* * *}$ & & $0.004(0.02)$ & $0.006(0.006)$ \\
\hline Multi-Liens & & $-0.08(0.02)^{* * *}$ & $-0.0002(0.01)$ & & $1.13(0.08)^{* * *}$ & $0.21(0.02)^{* * *}$ \\
\hline$\beta$ & & $0.98(0.004)^{* * *}$ & $0.98(0.004)^{* * *}$ & & $0.98(0.005)^{* * *}$ & $0.98(0.005)^{* * *}$ \\
\hline No. of Obs & & 270093 & 270093 & & 130356 & 130356 \\
\hline $\mathrm{R}^{2}$ & & 0.856 & 0.987 & & 0.963 & 0.996 \\
\hline
\end{tabular}

SUR with constraints that coefficients on monthly payment and $\hat{E}\left[V_{t+1}\left(s_{i, t+1}\right) \mid s_{i, t}, a_{i, t}\right]$ are the same between the payment and prepayment equations. Bootstrapped standard errors are reported to account for estimation errors in first-step policy functions and ex ante value functions. 
Table 10: Estimates after Controlling for Liquidity Shocks through Parametric Assumption

\begin{tabular}{|c|c|c|c|}
\hline & Default & Prepay & Pay \\
\hline FICO & $-1.2462(0.1315)^{* * *}$ & & \\
\hline MSA dummies & Included & & \\
\hline Housing Value & & $0.5242(0.3923)$ & $0.4394(0.2196) * *$ \\
\hline Monthly Payment & & $-0.1351(0.0530) * *$ & $-0.1351(0.0530) * *$ \\
\hline Prepayment Penalty & & $0.1424(0.0459) * * *$ & \\
\hline Income & & $0.004(0.0024)$ & $0.0066(0.0010) * * *$ \\
\hline Unemployment Rate & & $-0.2368(0.0097) * * *$ & $-0.0405(0.009) * * *$ \\
\hline Low Doc & & $-0.1053(0.0256) * * *$ & $-0.0475(0.0091) * * *$ \\
\hline Multiple Liens & & $0.008(0.0399)$ & $-0.0126(0.026)$ \\
\hline$\beta\left(\right.$ coeff on $\left.\hat{E}\left[V_{t+1}\left(s_{i, t+1}\right) \mid s_{i, t}, a_{i, t}\right]\right)$ & & $0.9336(0.0168) * * *$ & $0.9336(0.0168) * * *$ \\
\hline No. of Obs & & 198122 & 198122 \\
\hline $\mathrm{R}^{2}$ & & 0.7456 & 0.909 \\
\hline
\end{tabular}

SUR with constraints that coefficients on monthly payment and $\hat{E}\left[V_{t+1}\left(s_{i, t+1}\right) \mid s_{i, t}, a_{i, t}\right]$ are the same between the payment and prepayment equations. Bootstrapped standard errors are reported to account for estimation errors in first-step policy functions and ex ante value functions.

Table 11: Counterfactual Analyses

\begin{tabular}{|c|cccc|}
\hline Scenario & \multicolumn{2}{|c}{ Counterfactual } & \multicolumn{2}{c|}{ Baseline } \\
\hline & Default & Prepay & Default & Prepay \\
Scenario 1: Home Price Decline & 0.1129 & 0.4717 & 0.0983 & 0.4944 \\
Scenario 2: Home Price Increase & 0.2204 & 0.2635 & 0.2696 & 0.2177 \\
Scenario 3: Higher Credit Quality & 0.2329 & 0.2232 & 0.2696 & 0.2177 \\
Scenario 4: 10\% Principal Writedown & 0.1167 & 0.5783 & 0.1482 & 0.5536 \\
Scenario 5: 20\% Principal Writedown & 0.0914 & 0.5938 & 0.1482 & 0.5536 \\
Scenario 6: LTV Cap at 0.8 & 0.1316 & 0.5692 & 0.1482 & 0.5536 \\
Scenario 7: LTV Cap at 0.9 & 0.1458 & 0.556 & 0.1482 & 0.5536 \\
\hline
\end{tabular}

This table examines probability of eventual default/prepay by the end of 2009. The first (second) column reports predicted probability of eventual default or prepay by December 2009 under the specified counterfactual (baseline) scenario. The baseline default and prepayment probabilities differ across scenarios since different scenarios examine different subgroups. For instance, Scenarios 4-7 examine all loans while Scenario 1 examines loans originated in 2004. 
Table 12: Borrowers' Welfare, Ex Ante Values

\begin{tabular}{|c|cc|}
\hline Scenario & Counterfactual & Baseline \\
\hline Scenario 1: Home Price Decline & 0.5584 & 0.7167 \\
Scenario 2: Home Price Increase & 0.1716 & -0.1353 \\
Scenario 3: Higher Credit Quality & -0.0201 & -0.1353 \\
Scenario 4: 10\% Principal Writedown & -0.0744 & -0.3569 \\
Scenario 5: 20\% Principal Writedown & 0.2291 & -0.3569 \\
Scenario 6: LTV Cap at 0.8 & -0.273 & -0.3569 \\
Scenario 7: LTV Cap at 0.9 & -0.3456 & -0.3569 \\
\hline
\end{tabular}

This table compares borrowers' welfare under the specified counterfactual scenarios against welfare under the baseline. Our measure of welfare is the average ex ante values of borrowers. The baseline welfare figures differ across scenarios since different scenarios examine different subgroups. For instance, Scenarios 4-7 examine all loans while Scenario 1 examines loans originated in 2004.

Table 13: Borrowers' Welfare, One-Time Compensating Variation

\begin{tabular}{|c|c|}
\hline Scenario & Average OTCV per borrower \\
\hline Scenario 1: Home Price Decline & $-\$ 8976.7$ \\
Scenario 2: Home Price Increase & $\$ 16812.2$ \\
Scenario 3: Higher Credit Quality & $\$ 6414.8$ \\
Scenario 4: 10\% Principal Writedown & $\$ 16643.6$ \\
Scenario 5: 20\% Principal Writedown & $\$ 29510.7$ \\
Scenario 6: LTV Cap at 0.8 & $\$ 4932.2$ \\
Scenario 7: LTV Cap at 0.9 & $\$ 560.2$ \\
\hline
\end{tabular}




\section{Appendix}

\section{Proof of Theorem 2}

Using the joint cdf of the idiosyncratic payoff shocks, we introduce the following functions:

$$
\begin{aligned}
& \sigma_{0}\left(z_{1}, z_{2} ; c\right)=\int \mathbf{1}\left\{\varepsilon_{0} \geq z_{1}+\varepsilon_{1}, \varepsilon_{0} \geq z_{2}+\varepsilon_{2}\right\} F_{\varepsilon}(d \varepsilon \mid c), \\
& \sigma_{1}\left(z_{1}, z_{2} ; c\right)=\int \mathbf{1}\left\{z_{1}+\varepsilon_{1} \geq \varepsilon_{0}, z_{1}+\varepsilon_{1} \geq z_{2}+\varepsilon_{2}\right\} F_{\varepsilon}(d \varepsilon \mid c), \\
& \sigma_{2}\left(z_{1}, z_{2} ; c\right)=\int \mathbf{1}\left\{z_{2}+\varepsilon_{2} \geq \varepsilon_{0}, z_{2}+\varepsilon_{2} \geq z_{1}+\varepsilon_{1}\right\} F_{\varepsilon}(d \varepsilon \mid c) .
\end{aligned}
$$

We note that the introduced functions are known (given that we can normalize the distribution of the idiosyncratic shocks) and are monotone and differentiable in their arguments. Our result will be based on the following technical lemma.

\section{Lemma 1}

Under our assumptions, the system of equations

$$
\begin{aligned}
& \sigma_{0}\left(z_{1}, z_{2} ; c\right)=\bar{\sigma}_{0}(c), \\
& \sigma_{1}\left(z_{1}, z_{2} ; c\right)=\bar{\sigma}_{1}(c)
\end{aligned}
$$

has a unique solution for each $c$ if and only if $\bar{\sigma}_{0}(c)+\bar{\sigma}_{1}(c)<1$.

Proof:

Consider partial derivatives

$$
\begin{aligned}
& \frac{\partial \sigma_{0}\left(z_{1}, z_{2}\right)}{\partial z_{1}}=-\int_{-\infty}^{+\infty} \frac{\partial^{2} F_{\varepsilon}}{\partial \varepsilon_{0} \partial \varepsilon_{1}}\left(\varepsilon_{0}, \varepsilon_{0}-z_{1}, \varepsilon_{0}-z_{2}\right) d \varepsilon_{0} \\
& \frac{\partial \sigma_{0}\left(z_{1}, z_{2}\right)}{\partial z_{2}}=-\int_{-\infty}^{+\infty} \frac{\partial^{2} F_{\varepsilon}}{\partial \varepsilon_{0} \partial \varepsilon_{2}}\left(\varepsilon_{0}, \varepsilon_{0}-z_{1}, \varepsilon_{0}-z_{2}\right) d \varepsilon_{0}
\end{aligned}
$$

Similarly, we can find that

$$
\begin{aligned}
\frac{\partial \sigma_{1}\left(z_{1}, z_{2}\right)}{\partial z_{1}}= & \int_{-\infty}^{+\infty} \frac{\partial^{2} F_{\varepsilon}}{\partial \varepsilon_{0} \partial \varepsilon_{1}}\left(z_{1}+\varepsilon_{1}, \varepsilon_{1}, z_{1}-z_{2}+\varepsilon_{1}\right) d \varepsilon_{1} \\
& +\int_{-\infty}^{+\infty} \frac{\partial^{2} F_{\varepsilon}}{\partial \varepsilon_{1} \partial \varepsilon_{2}}\left(z_{1}+\varepsilon_{1}, \varepsilon_{1}, z_{1}-z_{2}+\varepsilon_{1}\right) d \varepsilon_{1} \\
& =\int_{-\infty}^{+\infty}\left(\frac{\partial^{2} F_{\varepsilon}}{\partial \varepsilon_{0} \partial \varepsilon_{1}}+\frac{\partial^{2} F_{\varepsilon}}{\partial \varepsilon_{1} \partial \varepsilon_{2}}\right)\left(\varepsilon_{0}, \varepsilon_{0}-z_{1}, \varepsilon_{0}-z_{2}\right) d \varepsilon_{0}
\end{aligned}
$$


and

$$
\frac{\partial \sigma_{1}\left(z_{1}, z_{2}\right)}{\partial z_{2}}=-\int_{-\infty}^{+\infty} \frac{\partial^{2} F_{\varepsilon}}{\partial \varepsilon_{1} \partial \varepsilon_{2}}\left(\varepsilon_{0}, \varepsilon_{0}-z_{1}, \varepsilon_{0}-z_{2}\right) d \varepsilon_{0}
$$

We assumed that the joint distribution of errors has a continuous density with a full support on $\mathbb{R}^{3}$. Provided that $\frac{\partial \sigma_{0}\left(z_{1}, z_{2}\right)}{\partial z_{1}} \frac{\partial \sigma_{0}\left(z_{1}, z_{2}\right)}{\partial z_{2}}>0$ the mapping $z_{1} \mapsto z_{2}$ implicitly defined by equation $\sigma_{0}\left(z_{1}, z_{2} ; c\right)=$ $\bar{\sigma}_{0}(c)$ is invertible for any $c$. Moreover, if we denote this mapping $z_{2}=m_{0}\left(z_{1}, \bar{\sigma}_{0}(c) ; c\right)$, then using the result regarding the derivative of the inverse function, we can conclude that

$$
\frac{\partial m_{0}\left(z_{1}, \bar{\sigma}_{0}(c) ; c\right)}{\partial z_{1}} \leq 0
$$

Similarly, we can define a map $z_{2}=m_{1}\left(z_{1}, \bar{\sigma}_{1}(c) ; c\right)$, then using the result regarding the derivative of the inverse function, we can conclude that

$$
\frac{\partial m_{1}\left(z_{1}, \bar{\sigma}_{1}(c) ; c\right)}{\partial z_{1}} \geq 0
$$

We can explore the asymptotic behavior of both maps. Consider $m_{0}$ first. Suppose that $z_{1} \rightarrow-\infty$. Then $\lim _{z_{1} \rightarrow-\infty} m_{0}\left(z_{1}, \bar{\sigma}_{0}(c) ; c\right)=z_{2}^{*}$, where $z_{2}^{*}$ solves $\int \mathbf{1}\left\{\varepsilon_{0} \geq z_{2}^{*}+\varepsilon_{2}\right\} F_{\varepsilon}(d \varepsilon \mid c)=\bar{\sigma}_{0}(c)$. Also let $z_{1}^{*}$ solve $\int \mathbf{1}\left\{\varepsilon_{0} \geq z_{1}^{*}+\varepsilon_{1}\right\} F_{\varepsilon}(d \varepsilon \mid c)=\bar{\sigma}_{0}(c)$. Then $\lim _{z_{1} \rightarrow z_{1}^{*}} m_{0}\left(z_{1}, \bar{\sigma}_{0}(c) ; c\right)=-\infty$.

Next consider $m_{1}$. Suppose that $z_{2}^{* *}$ is the solution of $\int \mathbf{1}\left\{\varepsilon_{1} \geq z_{2}^{* *}+\varepsilon_{2}\right\} F_{\varepsilon}(d \varepsilon \mid c)=\bar{\sigma}_{1}(c)$. Then as $z_{1} \rightarrow+\infty$, the map approaches asymptotically to the line: $m_{1}\left(z_{1}, \bar{\sigma}_{1}(c) ; c\right) \rightarrow z_{1}+z_{2}^{* *}$. Suppose that $z_{1}^{* *}$ is the solution of $\int \mathbf{1}\left\{z_{1}^{* *}+\varepsilon_{1} \geq \varepsilon_{0}\right\} F_{\varepsilon}(d \varepsilon \mid c)=\bar{\sigma}_{1}(c)$. Then $\lim _{z_{1} \rightarrow z_{1}^{* *}} m_{1}\left(z_{1}, \bar{\sigma}_{1}(c) ; c\right)=-\infty$. Thus $m_{0}$ is a continuous strictly decreasing mapping from $\left(-\infty, z_{1}^{*}\right]$ into $\left(-\infty, z_{2}^{*}\right]$ and $m_{1}$ is a continuous strictly increasing mapping from $\left[z_{1}^{* *},+\infty\right)$ into the real line.

Provided that both curves are continuous and monotone, they intersect if and only if their projections on $z_{1}$ and $z_{2}$ axes overlap. The projections on the $z_{2}$ axis are guaranteed to overlap $\left(\left(-\infty, z_{2}^{*}\right] \subset \mathbb{R}\right)$. The projections on the $z_{1}$ axis will overlap if and only if $z_{1}^{* *}<z_{1}^{*}$. Given that function $\sigma(z)=\int \mathbf{1}\left\{\varepsilon_{0}-\varepsilon_{1} \leq\right.$ $z\} F_{\varepsilon}(d \varepsilon \mid c)$ is strictly monotone in $z$, then $z_{1}^{* *}<z_{1}^{*}$ if and only if $\bar{\sigma}_{0}(c)+\bar{\sigma}_{1}(c)<1$.

This proves the statement of Lemma 1.

Next we can show that the model is nonparametrically identified. We introduce function

$$
\begin{aligned}
& \nu\left(z_{1}, z_{2} ; c\right)=\int\left(z_{1} \mathbf{1}\left\{z_{1}+\varepsilon_{1} \geq \varepsilon_{0}, z_{1}+\varepsilon_{1} \geq z_{2}+\varepsilon_{2}\right\}\right. \\
& \left.+z_{2} \mathbf{1}\left\{z_{2}+\varepsilon_{2} \geq \varepsilon_{0}, z_{2}+\varepsilon_{2} \geq z_{1}+\varepsilon_{1}\right\}\right) F_{\varepsilon}(d \varepsilon \mid c)+u(0 ; c)
\end{aligned}
$$


where the payoff from the default option $u(0 ; c)$ is a fixed known function according to the assumption of the theorem.

The observed probability distribution characterizes the conditional choice probabilities $\left\{\sigma_{k, t}(\cdot ; \cdot), k \in\right.$ $A\}$. Given the structure of the optimal solution, there is a direct link between the choice-specific value functions in period $t$ and the choice probability which is expressed through the distribution of the idiosyncratic payoff shocks. In particular, for each $s \in \mathcal{S}$ and $c \in \mathcal{C}$ and each $t \leq T$, we can write the system of identifying equations

$$
\begin{aligned}
& \sigma_{0}\left(V_{t}(1, s ; c)-u(0, s ; c), V_{t}(2, s ; c)-u(0, s ; c) ; c\right)=\sigma_{0, t}(s ; c) \\
& \sigma_{1}\left(V_{t}(1, s ; c)-u(0, s ; c), V_{t}(2, s ; c)-u(0, s ; c) ; c\right)=\sigma_{1, t}(s ; c) .
\end{aligned}
$$

Given the result of Lemma 1, we can solve for the choice-specific value functions $V_{t}(1, s ; c)$ and $V_{t}(2, s ; c)$ over $\mathcal{S}$ and $\mathcal{C}$.

The conditional distribution $s_{t+1} \mid s_{t}, a_{t}, c$ is observable. As a result, for each $k \in\{1,2\}$ and each $s$ and $c$ we can consider the system of equations in periods $t$ and $t^{\prime}<T$ :

$$
\begin{aligned}
& V_{t}(1, s ; c)=u(1, s ; c)+\beta E\left[\nu\left(V_{t+1}\left(1, s^{\prime} ; c\right)-u\left(0, s^{\prime} ; c\right), V_{t+1}\left(2, s^{\prime} ; c\right)-u\left(0, s^{\prime} ; c\right) ; c\right) \mid a_{t}=1, s, c\right], \\
& V_{t}(2, s ; c)=u(2, s ; c)+\beta E\left[\nu\left(V_{t+1}\left(1, s^{\prime} ; c\right)-u\left(0, s^{\prime} ; c\right), V_{t+1}\left(2, s^{\prime} ; c\right)-u\left(0, s^{\prime} ; c\right) ; c\right) \mid a_{t}=2, s, c\right], \\
& V_{t^{\prime}}(1, s ; c)=u(1, s ; c)+\beta E\left[\nu\left(V_{t^{\prime}+1}\left(1, s^{\prime} ; c\right)-u\left(0, s^{\prime} ; c\right), V_{t^{\prime}+1}\left(2, s^{\prime} ; c\right)-u\left(0, s^{\prime} ; c\right) ; c\right) \mid a_{t^{\prime}}=1, s, c\right] .
\end{aligned}
$$

This is a system of three linear equations with three unknowns $u(1, s ; c), u(2, s ; c)$ and $\beta$. We note that to set up this system of equations, we need to have observations for at least three periods (i.e., when $\left.t^{\prime}=t+1\right)$

Then simple differencing solves for the discount factor:

$$
\begin{aligned}
\beta= & \left(E\left[\nu\left(V_{t+1}\left(1, s^{\prime} ; c\right)-u\left(0, s^{\prime} ; c\right), V_{t+1}\left(2, s^{\prime} ; c\right)-u\left(0, s^{\prime} ; c\right) ; c\right) \mid a_{t}=1, s, c\right]\right. \\
& \left.-E\left[\nu\left(V_{t^{\prime}+1}\left(1, s^{\prime} ; c\right)-u\left(0, s^{\prime} ; c\right), V_{t^{\prime}+1}\left(2, s^{\prime} ; c\right)-u\left(0, s^{\prime} ; c\right) ; c\right) \mid a_{t^{\prime}}=1, s, c\right]\right)^{-1} \\
& \times\left[V_{t}(1, s ; c)-V_{t^{\prime}}(1, s ; c)\right] .
\end{aligned}
$$

The denominator in this expression is not equal to zero because of the assumption of the theorem that $\sigma_{k, t}(s ; c) \neq \sigma_{k, t^{\prime}}(s ; c)$ for at least two consecutive periods $t$ and $t^{\prime}$. We also can recover the per-period 
utility function as

$$
\begin{aligned}
u(1, s ; c)= & \left(E\left[\nu\left(V_{t+1}\left(1, s^{\prime} ; c\right)-u\left(0, s^{\prime} ; c\right), V_{t+1}\left(2, s^{\prime} ; c\right)-u\left(0, s^{\prime} ; c\right) ; c\right) \mid a_{t}=1, s, c\right]\right. \\
& \left.-E\left[\nu\left(V_{t^{\prime}+1}\left(1, s^{\prime} ; c\right)-u\left(0, s^{\prime} ; c\right), V_{t^{\prime}+1}\left(2, s^{\prime} ; c\right)-u\left(0, s^{\prime} ; c\right) ; c\right) \mid a_{t^{\prime}}=1, s, c\right]\right)^{-1} \\
& \times\left(V_{t^{\prime}}(1, s ; c) E\left[\nu\left(V_{t+1}\left(1, s^{\prime} ; c\right)-u\left(0, s^{\prime} ; c\right), V_{t+1}\left(2, s^{\prime} ; c\right)-u\left(0, s^{\prime} ; c\right) ; c\right) \mid a_{t}=1, s, c\right]\right. \\
& \left.-V_{t}(1, s ; c) E\left[\nu\left(V_{t^{\prime}+1}\left(1, s^{\prime} ; c\right)-u\left(0, s^{\prime} ; c\right), V_{t^{\prime}+1}\left(2, s^{\prime} ; c\right)-u\left(0, s^{\prime} ; c\right) ; c\right) \mid a_{t^{\prime}}=1, s, c\right]\right)
\end{aligned}
$$

Similarly, we can explicitly recover the utility $u(2, s ; c)$ for any $s$ and $c$ in their support. We note that if the discount factor is fixed, then we can identify the utility function from just two periods.

If the per-period payoff function in the last period coincides with the per-period payoff function in the previous periods $\left(u(\cdot, \cdot ; \cdot)=u_{T}(\cdot, \cdot ; \cdot)\right)$, then in the last period the choice specific values coincide with the utilities, meaning that $V_{T}(1, s ; c)=u(1, s ; c)$ and $V_{T}(2, s ; c)=u(2, s ; c)$. Both these utilities are recovered from just observing the last period choice probabilities. Then we can re-construct the ex ante value function of the last period using these estimates. We can take the first equation of the system considered before

$$
V_{T-1}(1, s ; c)=u(1, s ; c)+\beta E\left[\nu\left(u\left(1, s^{\prime} ; c\right)-u\left(0, s^{\prime} ; c\right), u\left(2, s^{\prime} ; c\right)-u\left(0, s^{\prime} ; c\right) ; c\right) \mid a_{T-1}=1, s, c\right],
$$

where the only remaining unknown is the discount factor. We can recover it as

$$
\beta=\frac{V_{T-1}(1, s ; c)-u(1, s ; c)}{E\left[\nu\left(u\left(1, s^{\prime} ; c\right)-u\left(0, s^{\prime} ; c\right), u\left(2, s^{\prime} ; c\right)-u\left(0, s^{\prime} ; c\right) ; c\right) \mid a_{T-1}=1, s, c\right]} .
$$

Therefore, in the special case where $u=u_{T}$, the discount factor as well as the utility functions are identified from just two periods, if one of the observed periods is the period of mortgage maturity $T$.

\section{Proof of Theorem 3}

Consider normalization $u(0, s ; c)$. Then, for instance

$$
\sigma_{0, t}(s ; c)=\int \mathbf{1}\left\{u(0, s ; c)+\varepsilon_{0, t} \geq V_{t}(1, s ; c)+\varepsilon_{1, t}, u(0, s ; c)+\varepsilon_{0, t} \geq V_{t}(2, s ; c)+\varepsilon_{2, t}\right\} F_{\varepsilon}(d \varepsilon \mid c) .
$$

Using the notation in the proof of the previous theorem, we can then express

$$
\sigma_{0, t}(s ; c)=\sigma_{0}\left(V_{t}(1, s ; c)-u(0, s ; c), V_{t}(2, s ; c)-u(0, s ; c) ; c\right) .
$$


We can also provide similar expressions for other choices. Then we solve the system of equations

$$
\begin{aligned}
& \sigma_{0, t}(s ; c)=\sigma_{0}\left(V_{t}(1, s ; c)-u(0, s ; c), V_{t}(2, s ; c)-u(0, s ; c) ; c\right), \\
& \sigma_{1, t}(s ; c)=\sigma_{1}\left(V_{t}(1, s ; c)-u(0, s ; c), V_{t}(2, s ; c)-u(0, s ; c) ; c\right)
\end{aligned}
$$

to recover the value functions. We note that the recovered differences $V_{t}(k, s ; c)-u(0, s ; c)$ are invariant to the choice of $u(0, s ; c)$ as they are directly recovered from the data.

The ex ante value function can be recovered as

$$
\begin{aligned}
V_{t}(s ; c)=\int( & \left(V_{t}(1, s ; c)-u(0, s ; c)\right) \mathbf{1}\left\{V_{t}(1, s ; c)-u(0, s ; c)+\varepsilon_{1, t} \geq \varepsilon_{0, t}, V_{t}(1, s ; c)+\varepsilon_{1, t}\right. \\
& \left.\geq V_{t}(2, s ; c)+\varepsilon_{2, t}\right\} \\
+ & \left(V_{t}(2, s ; c)-u(0, s ; c)\right) \mathbf{1}\left\{V_{t}(2, s ; c)-u(0, s ; c)+\varepsilon_{2, t} \geq \varepsilon_{0, t}, V_{t}(2, s ; c)+\varepsilon_{2, t}\right. \\
& \left.\left.\geq V_{t}(1, s ; c)+\varepsilon_{1, t}\right\}\right) F_{\varepsilon}(d \varepsilon \mid c) \\
+ &
\end{aligned}
$$

where function $\mathbf{V}_{t}(\cdot ; \cdot)$ is invariant to the choice of the default payoff (it is determined by the observed choice probabilities). The system of equations identifying the per-period payoffs takes the form

$$
\begin{aligned}
& V_{t}(1, s ; c)=u(1, s ; c)+\beta E\left[\mathbf{V}_{t+1}\left(s^{\prime} ; c\right)+u\left(0, s^{\prime} ; c\right) \mid a_{t}=1, s, c\right] \\
& V_{t}(2, s ; c)=u(2, s ; c)+\beta E\left[\mathbf{V}_{t+1}\left(s^{\prime} ; c\right)+u\left(0, s^{\prime} ; c\right) \mid a_{t}=2, s, c\right] \\
& V_{t^{\prime}}(1, s ; c)=u(1, s ; c)+\beta E\left[\mathbf{V}_{t^{\prime}+1}\left(s^{\prime} ; c\right)+u\left(0, s^{\prime} ; c\right) \mid a_{t^{\prime}}=1, s, c\right] .
\end{aligned}
$$

Provided that $u(0, s ; c)$ is normalized to a fixed function, taking the difference between the first and the third equation allows us to express the discount factor as

$$
\beta=\frac{V_{t}(1, s ; c)-u(0, s ; c)-\left(V_{t^{\prime}}(1, s ; c)-u(0, s ; c)\right)}{E\left[\mathbf{V}_{t+1}\left(s^{\prime} ; c\right) \mid a_{t}=1, s, c\right]-E\left[\mathbf{V}_{t^{\prime}+1}\left(s^{\prime} ; c\right) \mid a_{t^{\prime}}=1, s, c\right]} .
$$

Provided that the numerator and the denominator are invariant with respect to the choice of the default utility (as they can be directly recovered from the observed choice probabilities), the discount factor will not depend on that choice either. Having obtained the discount factor, we can focus on the first two 
equations of the considered system and re-cast them to the form

$$
\begin{aligned}
& V_{t}(1, s ; c)-u(0, s ; c)-\beta E\left[\mathbf{V}_{t+1}\left(s^{\prime} ; c\right) \mid a_{t}=1, s, c\right]=u(1, s ; c)-u(0, s ; c)+\beta E\left[u\left(0, s^{\prime} ; c\right) \mid a_{t}=1, s, c\right], \\
& V_{t}(2, s ; c)-u(0, s ; c)-\beta E\left[\mathbf{V}_{t+1}\left(s^{\prime} ; c\right) \mid a_{t}=2, s, c\right]=u(2, s ; c)-u(0, s ; c)+\beta E\left[u\left(0, s^{\prime} ; c\right) \mid a_{t}=2, s, c\right] .
\end{aligned}
$$

The left-hand side of this system is immune to the choice of the default utility. As result, the right-hand side should be invariant too. In other words, for any two choices $u(0, s ; c)$ and $u^{\prime}(0, s ; c)$,

$u(k, s ; c)-u(0, s ; c)+\beta E\left[u\left(0, s^{\prime} ; c\right) \mid a_{t}=k, s, c\right]=u^{\prime}(k, s ; c)-u^{\prime}(0, s ; c)+\beta E\left[u^{\prime}\left(0, s^{\prime} ; c\right) \mid a_{t}=k, s, c\right]$.

Thus, the gap between the utilities from different options depends on the choice of the default utility

$$
u(k, s ; c)-u(0, s ; c)-\left(u^{\prime}(k, s ; c)-u^{\prime}(0, s ; c)\right)=\beta E\left[u^{\prime}\left(0, s^{\prime} ; c\right)-u\left(0, s^{\prime} ; c\right) \mid a_{t}=k, s, c\right]
$$

for $k=1,2$.

If the last period choice probability is observed and $u=u_{T}$, then we can complement the system of Bellman equations with the expressions for the choice probabilities of the last period. Those choice probabilities identify the differences $u(1, s ; c)-u(0, s ; c)$ and $u(2, s ; c)-u(0, s ; c)$. Thus, we can identify the

pair of conditional expectations $E\left[u\left(0, s^{\prime} ; c\right) \mid a_{t}=1, s, c\right]$ and $E\left[u\left(0, s^{\prime} ; c\right) \mid a_{t}=2, s, c\right]$ from the system of linear equations that we constructed before:

$$
\begin{aligned}
& \beta E\left[u\left(0, s^{\prime} ; c\right) \mid a_{t}=1, s, c\right]=V_{t}(1, s ; c)-u(0, s ; c)-\beta E\left[\mathbf{V}_{t+1}\left(s^{\prime} ; c\right) \mid a_{t}=1, s, c\right]-u(1, s ; c)+u(0, s ; c), \\
& \beta E\left[u\left(0, s^{\prime} ; c\right) \mid a_{t}=2, s, c\right]=V_{t}(2, s ; c)-u(0, s ; c)-\beta E\left[\mathbf{V}_{t+1}\left(s^{\prime} ; c\right) \mid a_{t}=2, s, c\right]-u(2, s ; c)+u(0, s ; c) .
\end{aligned}
$$

This system of equations represents a familiar nonlinear instrumental variable problem which is known to be an ill-posed inverse problem. It has a unique solution and, thus, the utility from default is identified, under the completeness condition that is discussed in Newey and Powell (2003), and Chen, Chernozhukov, Lee and Newey (2011). Therefore, the utilities from all choices $u(0, s ; c), u(1, s ; c)$, and $u(2, s ; c)$ are identified along with the discount factor $\beta$ in this case.

\section{Proof of Theorem 4}

In this proof by $n$ we denote the sample size corresponding to the borrowers observed with $t$ periods from mortgage origination with the heterogeneity characteristic equal to $c$. We introduce the notation for 
the trinomial logit function $\ell\left(z_{1}, z_{2}\right)=\frac{\exp \left(z_{1}\right)}{1+\exp \left(z_{1}\right)+\exp \left(z_{2}\right)}$. By $\tilde{\sigma}_{k, t}^{L}(s ; c)$ we denote the choice probability

$$
\tilde{\sigma}_{k, t}^{L}(s ; c)=\ell\left(\tilde{r}^{L \prime}(t, k, c) q^{L}(s), \tilde{r}^{L \prime}(t, j, c) q^{L}(s)\right), \quad j \neq k
$$

where $\tilde{r}^{L}(t, k, c)$ are the coefficients of the projection of the probability ratio $\log \frac{\sigma_{k, t}(s ; c)}{\sigma_{0, t}(s ; c)}$ on $L$ first orthogonal polynomials. We also denote $\tilde{\sigma}_{0, t}^{L}(s ; c)=1-\tilde{\sigma}_{1, t}^{L}(s ; c)-\tilde{\sigma}_{2, t}^{L}(s ; c)$. We note that $\frac{\partial \ell}{\partial z_{1}}, \frac{\partial \ell}{\partial z_{2}} \leq \frac{1}{2}$. Thus, $\frac{1}{2}$ is a uniform Lipschitz constant and

$$
\begin{aligned}
\sup _{s \in \mathcal{S}} \mid \tilde{\sigma}_{k, t}^{L}(s ; c) & -\sigma_{k, t}(s ; c)\left|=\sup _{s \in \mathcal{S}}\right| \ell\left(\log \frac{\tilde{\sigma}_{k, t}^{L}(s ; c)}{\tilde{\sigma}_{0, t}^{L}(s ; c)}, \log \frac{\tilde{\sigma}_{j, t}^{L}(s ; c)}{\tilde{\sigma}_{0, t}^{L}(s ; c)}\right)-\ell\left(\log \frac{\sigma_{k, t}(s ; c)}{\sigma_{0, t}(s ; c)}, \log \frac{\sigma_{j, t}(s ; c)}{\sigma_{0, t}(s ; c)}\right) \mid \\
& \leq \frac{1}{2} \sqrt{\sup _{s \in \mathcal{S}}\left|\log \frac{\tilde{\sigma}_{1, t}^{L}(s ; c)}{\tilde{\sigma}_{0, t}^{L}(s ; c)}-\log \frac{\sigma_{1, t}(s ; c)}{\sigma_{0, t}(s ; c)}\right|^{2}+\sup _{s \in \mathcal{S}}\left|\log \frac{\tilde{\sigma}_{2, t}^{L}(s ; c)}{\tilde{\sigma}_{0, t}^{L}(s ; c)}-\log \frac{\sigma_{2, t}(s ; c)}{\sigma_{0, t}(s ; c)}\right|^{2}}=O\left(L^{-\alpha}\right) .
\end{aligned}
$$

This guarantees the quality of approximation of the choice probability using a logit transformation of the series expansion.

Now we omit index $t$ in the variables (whenever the period of time under consideration is known) and construct function

$$
\begin{aligned}
\rho\left(a_{i}, s_{i} ; r_{1}^{L}, r_{2}^{L}\right)= & \left(\mathbf{1}\left\{a_{i}=1\right\}-\mathbf{1}\left\{a_{i}=0\right\}\right) \ell\left(r_{1}^{L \prime} q^{L}\left(s_{i}\right), r_{2}^{L \prime} q^{L}\left(s_{i}\right)\right) \\
& +\left(\mathbf{1}\left\{a_{i}=2\right\}-\mathbf{1}\left\{a_{i}=0\right\}\right) \ell\left(r_{2}^{L \prime} q^{L}\left(s_{i}\right), r_{1}^{L \prime} q^{L}\left(s_{i}\right)\right) .
\end{aligned}
$$

Then we can express the sample quasi-likelihood as

$$
\widehat{Q}\left(r_{1}^{L}, r_{2}^{L}\right)=E_{n}\left[\rho\left(a_{i}, s_{i} ; r_{1}^{L}, r_{2}^{L}\right)\right]+E_{n}\left[\mathbf{1}\left\{a_{i}=0\right\}\right]
$$

where we adopted the notation from the empirical process theory where $E_{n}[\cdot]=\frac{1}{n} \sum_{i=1}^{n}$. Also introduce the population likelihood with the series expansion

$$
Q\left(r_{1}^{L}, r_{2}^{L}\right)=E\left[\rho\left(a_{i}, s_{i} ; r_{1}^{L}, r_{2}^{L}\right)\right]+E\left[\mathbf{1}\left\{a_{i}=0\right\}\right]
$$

Consider function

$$
f\left(a_{i}, s_{i} ; r_{1}^{L}, r_{2}^{L}, \tilde{r}_{1}^{L}, \tilde{r}_{2}^{L}\right)=\rho\left(a_{i}, s_{i} ; r_{1}^{L}, r_{2}^{L}\right)-\rho\left(a_{i}, s_{i} ; \tilde{r}_{1}^{L}, \tilde{r}_{2}^{L}\right)-E\left[\rho\left(a_{i}, s_{i} ; r_{1}^{L}, r_{2}^{L}\right)\right]+E\left[\rho\left(a_{i}, s_{i} ; \tilde{r}_{1}^{L}, \tilde{r}_{2}^{L}\right)\right] .
$$


Provided that we established that function $\ell(\cdot, \cdot)$ is Lipschitz, we can evaluate

$$
\operatorname{Var}\left(f\left(a_{i}, s_{i} ; r_{1}^{L}, r_{2}^{L}, \tilde{r}_{1}^{L}, \tilde{r}_{2}^{L}\right)\right)=O\left(L \sup _{p=1,2, l \leq L}\left\|r_{p, l}-\tilde{r}_{p, l}\right\|\right)=O(L)
$$

Next we impose a technical assumption that allows us to establish consistency of estimator (3).

\section{ASSUMPTION 4}

Consider the class of functions indexed by $n$

$$
\mathcal{F}_{n}=\left\{f\left(\cdot, \cdot ; r_{1}^{L_{n}}, r_{2}^{L_{n}}, \tilde{r}_{1}^{L_{n}}, \tilde{r}_{2}^{L_{n}}\right)-E\left[f\left(\cdot, \cdot ; r_{1}^{L_{n}}, r_{2}^{L_{n}}, \tilde{r}_{1}^{L_{n}}, \tilde{r}_{2}^{L_{n}}\right)\right], r_{l, p} \in \Theta, l \leq L_{n}, p=1,2\right\}
$$

where $\Theta$ is the compact subset of $\mathbb{R}$ and $\tilde{r}_{1}^{L_{n}}$ and $\tilde{r}_{2}^{L_{n}}$ are the coefficients of projections of population probability ratios on $L_{n}$ series terms. Then for each $L_{n} \rightarrow \infty$ such that $n /\left(L_{n} \log n\right) \rightarrow \infty$ the $\mathbf{L}_{1}$ covering number for class $\mathcal{F}_{n}, N$, has the following bound

$$
\log N\left(\delta, \mathcal{F}_{n}, \mathbf{L}_{1}\right) \leq A n^{r_{0}} \log \frac{1}{\delta}
$$

where $0<r_{0} \leq \frac{3}{4}$ and $r_{0} \downarrow 0$ is assumed to correspond to the factor $\log n$.

This is the condition restricting the complexity of the functions created by logit transformations of series expansions. By construction any $f \in \mathcal{F}_{n}$ is bounded $|f|<1<\infty$. We established that $\operatorname{Var}(f)=$ $O\left(L_{n}\right)$ for $f \in \mathcal{F}_{n}$. The symmetrization inequality (30) in Pollard (1984) holds if $\varepsilon_{n} /\left(16 n \mu_{n}^{2}\right) \leq \frac{1}{2}$. This will occur if $\frac{n \epsilon_{n}}{N^{2}} \rightarrow \infty$. Provided that the symmetrization inequality holds, we can follow the steps of Theorem 37 in Pollard (1984) to establish the tail bound on the deviations of the sample average of $f$ via a combination of the Hoeffding inequality and the covering number for the class $\mathcal{F}_{n}$. As a result, we obtain that

$$
\begin{aligned}
& P\left(\sup _{f \in \mathcal{F}_{n}} \frac{1}{n}\left\|E_{n}[f(\cdot)]\right\|>8 \mu_{n}\right) \\
& \leq 2 \exp \left(A n^{r_{0}} \log \frac{1}{\mu_{n}}\right) \exp \left(-\frac{1}{128} \frac{n \mu_{n}^{2}}{L_{n}}\right)+P\left(\sup _{f \in \mathcal{F}_{n}} \frac{1}{n}\left\|E_{n}[f(\cdot)]^{2}\right\|>64 L_{n}\right) .
\end{aligned}
$$

The second term can be evaluated with the aid of Lemma 33 in Pollard (1984):

$$
P\left(\sup _{f \in \mathcal{F}_{n}} \frac{1}{n}\left\|E_{n}[f(\cdot)]^{2}\right\|>64 L_{n}\right) \leq 4 \exp \left(A n^{2 r_{0}} \log \frac{1}{L_{n}}\right) \exp \left(-n L_{n}\right)
$$


As a result, we find that

$$
\begin{aligned}
& P\left(\sup _{f \in \mathcal{F}_{n}} \frac{1}{n}\left\|E_{n}[f(\cdot)]\right\|>8 \mu_{n}\right) \\
& \leq 2 \exp \left(A n^{r_{0}} \log \frac{1}{\mu_{n}}\right) \exp \left(-\frac{1}{128} \frac{n \mu_{n}^{2}}{L_{n}}\right)+4 \exp \left(A n^{r_{0}} \log \frac{1}{L_{n}}-n L_{n}\right) .
\end{aligned}
$$

We start the analysis with the first term. Consider the case with $r_{0}>0$. Then the log of the first term takes the form

$$
A n^{r_{0}} \log \left(1 / \mu_{n}\right)-\frac{1}{128} \frac{n \mu_{n}^{2}}{L_{n}}
$$

Then one needs that $\frac{n \mu_{n}^{2}}{L_{n} n^{r_{0}} \log n} \rightarrow \infty$ if $r_{0}>0$ and $\frac{n \mu_{n}^{2}}{L_{n} \log ^{2} n} \rightarrow \infty$ if $r_{0} \downarrow 0$. Hence the first term is of $o(1)$. This condition also guarantees that the second term vanishes. We note also that the CLT applies to the term $E_{n}\left[\mathbf{1}\left\{a_{i}=0\right\}\right]=E\left[\mathbf{1}\left\{a_{i}=0\right\}\right]+O_{p}\left(\frac{1}{\sqrt{n}}\right)$. Now for some slowly diverging sequence $\delta_{n} \rightarrow \infty$ such that $\mu_{n}=\delta_{n} \sqrt{\frac{L_{n} n^{r} 0 \log n}{n}} \rightarrow 0$, we establish that

$$
\sup _{\left(r_{1}^{L_{n}}, r_{2}^{L_{n}}\right) \in \Theta^{L_{n}} \times \Theta^{L_{n}}}\left\|\widehat{Q}\left(r_{1}^{L}, r_{2}^{L}\right)-Q\left(r_{1}^{L}, r_{2}^{L}\right)+\widehat{Q}\left(\tilde{r}_{1}^{L}, \tilde{r}_{2}^{L}\right)-Q\left(\tilde{r}_{1}^{L}, r_{2}^{L}\right)\right\|=O_{p}\left(\mu_{n}+\frac{1}{\sqrt{n}}\right)=o_{p}(1) .
$$

Thus, the sample quasi-likelihood converges uniformly to the population quasi-likelihood and the estimated choice probabilities are uniformly consistent over $\mathcal{S}$. To establish the rate for the estimated choice probabilities, we consider a neighborhood of the population projections defined by $\sup _{p=1,2, l \leq L_{n}}\left\|r_{p, l}-\tilde{r}_{p, l}\right\| \leq$ $\varepsilon$. Using Lemma 2.3.1 from van der Vaart and Wellner (1996), we can find that

$$
E\left[\sup _{f \in \mathcal{F}_{n}} \sqrt{n} E_{n}[f(\cdot)]\right] \leq C n^{r_{0} / 2} \sqrt{L_{n}} \varepsilon \log \frac{1}{\sqrt{L_{n}} \varepsilon}
$$

for some constant $C$. Using Theorem 3.4.1 from van der Vaart and Wellner (1996) and the derived inequality, we can express the convergence rate for the estimated parameters of the approximated choice probabilities as $\rho_{n}^{2} n^{r_{0} / 2} \sqrt{L_{n}} \frac{1}{\rho_{n}} \log \frac{\rho_{n}}{\sqrt{L_{n}}} \leq \sqrt{n}$. Then

$$
\sup _{s \in \mathcal{S}}\left\|\widehat{\sigma}_{k, t}(s ; c)-\tilde{\sigma}_{k, t}(s ; c)\right\|=O_{p}\left(\frac{L_{n}}{\rho_{n}}\right) .
$$

To attain the rate $o_{p}\left(n^{-1 / 4}\right)$ we need to assure that $\frac{L_{n}}{\rho_{n}}=o\left(n^{-1 / 4}\right)$. To assure the $n^{-1 / 4}$ we choose $\delta_{n} \rightarrow 0$ and set $L_{n}=\delta_{n} n^{-1 / 4} \rho_{n}$. Then the rate constraint can be re-written as

$$
\rho_{n}^{2} n^{-3 / 8+r_{0} / 2} \frac{\log \frac{n^{1 / 4} \sqrt{\rho_{n}}}{\sqrt{\delta_{n}}}}{\frac{n^{1 / 4} \sqrt{\rho_{n}}}{\sqrt{\delta_{n}}}} \leq \sqrt{n}
$$


Provided that $\lim _{x \rightarrow \infty} \log x / x=0$, we conclude that $\rho_{n}=O\left(n^{7 / 8-r_{0} / 2}\right)$, meaning that $L_{n}=o\left(n^{5 / 8-r_{0} / 2}\right)$. We note that the slowest rate for the choice of $L_{n}$ has to satisfy

$$
\frac{n^{1-r_{0}} \mu_{n}^{2}}{L_{n} \log n} \rightarrow \infty
$$

for $\mu_{n} \rightarrow 0$. Thus, the estimator with rate $o\left(n^{-1 / 4}\right)$ is plausible if $r_{0}<3 / 4$. Using the triangle inequality and our previous result, we find that

$$
\sup _{s \in \mathcal{S}}\left\|\widehat{\sigma}_{k, t}(s ; c)-\sigma_{k, t}(s ; c)\right\|=O_{p}\left(\frac{L_{n}}{\rho_{n}}+L_{n}^{-\alpha}\right)=o_{p}\left(n^{-1 / 4}\right)
$$

if $\alpha \geq 1$.

\section{Expression for the Asymptotic Variance of the Structural Estimator}

We introduce

$$
J_{k}\left(\sigma_{0, t}, \sigma_{1, t}, \sigma_{0, t+1}, \sigma_{1, t+1}, s ; c\right)=\left(\frac{\partial F_{k}}{\partial \sigma_{0, t}}, \frac{\partial F_{k}}{\partial \sigma_{1, t}}, \frac{\partial F}{\partial \sigma_{0, t+1}}, \frac{\partial F}{\partial \sigma_{1, t+1}}\right)^{\prime}
$$

and $J(s ; c)=\left(J_{1}(s ; c), J_{2}(s ; c)\right)^{\prime}$,

$$
\begin{aligned}
& M(s ; c)= \\
& E\left[\left(\begin{array}{cccc}
\frac{\partial u\left(s_{t} ; \theta(1, c)\right)}{\partial \theta(1, c)} & 0 & -\frac{\partial u\left(s_{t} ; \theta(0, c)\right)}{\partial \theta(0, c)}+\beta \frac{\partial u\left(s_{t+1} ; \theta(0, c)\right)}{\partial \theta(0, c)} & F\left(s_{t+1} ; c\right)+u\left(s_{t+1} ; \theta(0, c)\right) \\
0 & \frac{\partial u\left(s_{t} ; \theta(2, c)\right)}{\partial \theta(2, c)} & -\frac{\partial u\left(s_{t} ; \theta(0, c)\right)}{\partial \theta(0, c)}+\beta \frac{\partial u\left(s_{t+1} ; \theta(0, c)\right)}{\partial \theta(0, c)} & F\left(s_{t+1} ; c\right)+u\left(s_{t+1} ; \theta(0, c)\right)
\end{array}\right) \mid s_{t}=s, c\right],
\end{aligned}
$$

as well as

$$
\Omega(s ; c)=\operatorname{Var}\left(\left(\widehat{\sigma}_{0, t}\left(s_{t} ; c\right), \widehat{\sigma}_{1, t}\left(s_{t} ; c\right), \widehat{\sigma}_{0, t+1}\left(s_{t+1} ; c\right), \widehat{\sigma}_{1, t+1}\left(s_{t+1} ; c\right)\right)^{\prime} \mid s_{t}=s, c\right) .
$$

Then, the variance of the second-stage estimates is determined by the sampling noise and the error from the first stage estimates:

$$
V=E\left[M\left(s_{t} ; c\right)^{-1}\left(E\left[Z_{t}^{\prime} \operatorname{Var}\left(\epsilon_{t} \mid s_{t}\right) Z_{t} \mid s_{t}\right]+J\left(s_{t} ; c\right) \Omega\left(s_{t} ; c\right) J\left(s_{t} ; c\right)^{\prime}\right) M\left(s_{t} ; c\right)^{-1 \prime} \mid c\right]
$$

As an alternative to using the asymptotic formula, we can use the subsampling approach to estimate the variance. 